\title{
Human Fungal Pathogens of Mucorales and Entomophthorales
}

\author{
Leonel Mendoza ${ }^{1,2}$, Raquel Vilela ${ }^{2,3,4}$, Kerstin Voelz $^{5,6}$, Ashraf S. Ibrahim ${ }^{7,8}$, Kerstin Voigt $^{9}$, \\ and Soo Chan Lee ${ }^{10}$ \\ ${ }^{1}$ Microbiology and Molecular Genetics, Michigan State University, East Lansing, Michigan 48424-1031 \\ ${ }^{2}$ Biomedical Laboratory Diagnostics, Michigan State University, East Lansing, Michigan 48424-1031 \\ ${ }^{3}$ Faculty of Pharmacy, Federal University of Minas Gerais (UFMG), Minas Gerais, CEP33400000 \\ Belo Horizonte, Brazil \\ ${ }^{4}$ Belo Horizonte Brazil; Superior Institute of Medicine (ISMD), Minas Gerais, CEP33400000 \\ Belo Horizonte, Brazil \\ ${ }^{5}$ Institute of Microbiology and Infection \& School of Biosciences, University of Birmingham, Birmingham \\ B15 2TT, United Kingdom \\ ${ }^{6}$ The National Institute of Health Research Surgical Reconstruction and Microbiology Research Centre, \\ Queen Elizabeth Hospital Birmingham, Birmingham, United Kingdom B15 2WB \\ ${ }^{7}$ Division of Infectious Diseases, Harbor-University of California Los Angeles Medical Center, St. John's \\ Cardiovascular Research Center, Los Angeles Biomedical Research Institute at Harbor-UCLA Medical \\ Center, Torrance, California 90502 \\ ${ }^{8}$ David Geffen School of Medicine at UCLA, Los Angeles, California 90095 \\ ${ }^{9}$ Jena Microbial Resource Collection, Leibniz Institute for Natural Product Research and Infection Biology \\ and University of Jena, Faculty of Biology and Pharmacy, Institute of Microbiology, Neugasse 25, 07743 \\ Jena, Germany \\ ${ }^{10}$ Department of Molecular Genetics and Microbiology, Duke University Medical Center, Durham, \\ North Carolina 27710 \\ Correspondence: soochan.lee@duke.edu
}

In recent years, we have seen an increase in the number of immunocompromised cohorts as a result of infections and/or medical conditions, which has resulted in an increased incidence of fungal infections. Although rare, the incidence of infections caused by fungi belonging to basal fungal lineages is also continuously increasing. Basal fungal lineages diverged at an early point during the evolution of the fungal lineage, in which, in a simplified four-phylum fungal kingdom, Zygomycota and Chytridiomycota belong to the basal fungi, distinguishing them from Ascomycota and Basidiomycota. Currently there are no known human infections caused by fungi in Chytridiomycota; only Zygomycotan fungi are known to infect humans. Hence, infections caused by zygomycetes have been called zygomycosis, and the term "zygomycosis" is often used as a synonym for "mucormycosis." In the four-phylum fungal kingdom system, Zygomycota is classified mainly based on morphology, including the ability to form coenocytic (aseptated) hyphae and zygospores (sexual spores). In the Zygomycota, there are 10 known orders, two of which, the Mucorales and Entomophthorales, contain species that can infect humans, and the infection has historically been known as zygomy-

Editors: Arturo Casadevall, Aaron P. Mitchell, Judith Berman, Kyung J. Kwon-Chung, John R. Perfect, and Joseph Heitman Additional Perspectives on Human Fungal Pathogens available at www.perspectivesinmedicine.org

Copyright (C) 2015 Cold Spring Harbor Laboratory Press; all rights reserved; doi: 10.1101/cshperspect.a019562 Cite this article as Cold Spring Harb Perspect Med 2015;5:a019562 


\section{Mendoza et al.}

cosis. However, recent multilocus sequence typing analyses (the fungal tree of life [AFTOL] project) revealed that the Zygomycota forms not a monophyletic clade but instead a polyphyletic clade, whereas Ascomycota and Basidiomycota are monophyletic. Thus, the term "zygomycosis" needed to be further specified, resulting in the terms "mucormycosis" and "entomophthoramycosis." This review covers these two different types of fungal infections.

\section{MUCORALES AND MUCORMYCOSIS}

$M$ ucoralean fungi reproduce both sexually and asexually. The asexual sporangiospores are formed in a globe-like structure called the sporangium on the apex of sporangiophore (Fig. 1). The sporangiospores then disperse and, on appropriate conditions, germinate to produce a mycelial complex. Most of the pathogenic Mucorales are heterothallic, and in their sexual development, hyphae of the two different mating types $[(-)$ and $(+)]$ sense each other and undergo fusion to form zygospores, which later
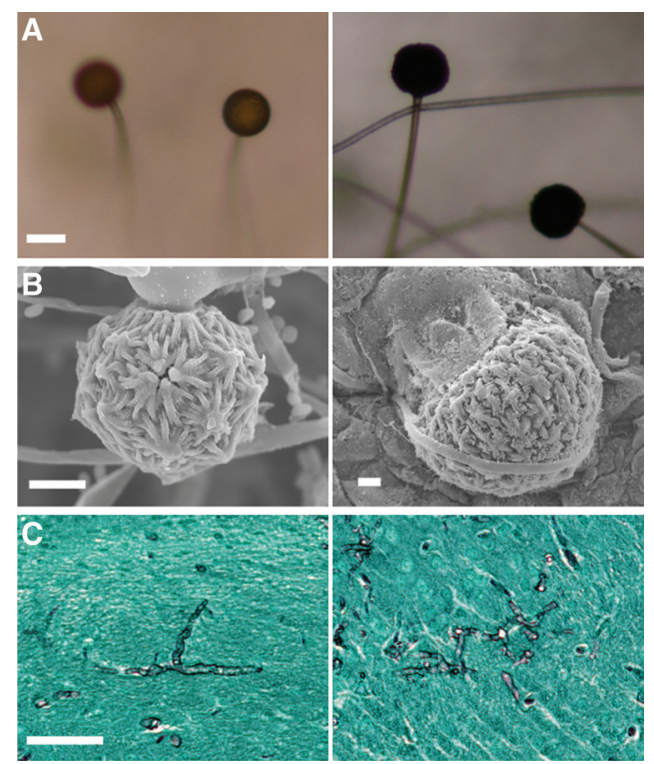

Figure 1. Morphology of Mucor circinelloides (left) and Rhizopus oryzae (right). (A) Sporangia form at the apices of sporangiophores and contain the asexual sporangiospores. (B) Zygospores formed during mating. (Figures adapted from Li et al. 2011 [left] and Gryganskyi et al. 2010 [right], respectively.) (C) Hyphae in the brains of infected mice. The tissue specimens were stained with Gomori's methenamine silver at $48 \mathrm{~h}$ postinfection. Scale bars, $50 \mu \mathrm{m}(A) ; 100$ $\mu \mathrm{m}(B, C)$. germinate to form a sporangium at the apex culminating in sexual meiospores. The formation of zygospores requires two compatible mating types, and it takes a considerable amount of time for the zygospores to germinate (reviewed in Lee et al. 2010). Therefore, the asexual sporangiospores may serve as the major source of dissemination and infection.

Mucormycosis is an infection caused by fungi that belong to the Mucorales order. Infection sites include the lungs, rhinocerebral spaces, sinuses, soft tissue, skin, gastrointestinal tract, and bloodstream (Dromer and McGinnis 2003; Ibrahim and Spellberg 2006). The predicted economic burden in the U.S. health care system caused by mucormycosis is $\sim \$ 100,000$ per case (Ibrahim et al. 2008a). Although mucormycosis has long been considered a rare fungal infection, advances in medical care and an increasingly aging population have resulted in a recent increase in the incidence (Roden et al. 2005; Chayakulkeeree et al. 2006; Lanternier and Lortholary 2009; Roilides et al. 2009; Kontoyiannis et al. 2010; Petrikkos et al. 2012). Enhanced management of susceptible individuals with predisposing conditions (e.g., diabetes, iron overload, immune-suppressive therapy, cancer, and trauma injury [Chayakulkeeree et al. 2006]) has improved patient prognosis while potentially allowing for the establishment of opportunistic mucormycosis. Consequently, mucormycosis is the second-most-common mold infection in hematological malignancy and transplant patients, and the mortality rates are unacceptably high, with $>90 \%$ mortality in disseminated infections (Ribes et al. 2000; Roden et al. 2005; Lanternier et al. 2012b).

The etiologic agents of mucormycosis include Rhizopus spp., Mucor spp., Lichtheimia ( previously Absidia) spp., Cunninghamella, Rhizomucor, and Apophysomyces spp., among others (Chayakulkeeree et al. 2006; Ibrahim and Spell- 
berg 2006; Neblett Fanfair et al. 2012). Among 50 mucormycosis cases in solid organ transplant recipients, Mucor spp. accounted for 37\% of cases, followed by Rhizopus spp. (35\%) and Mycocladus (synonym of Lichtheimia) (13\%) (Singh et al. 2009). In a European survey of 230 cases, Rhizopus spp. accounted for $24 \%$ of cases, followed by Mucor spp. (22\%) and Lichtheimia spp. (14\%) (Petrikkos 2008). In a survey of 75 cases in India, Rhizopus spp. (69\%) were the most common, followed by Apophysomyces spp. (19\%) (Chakrabarti et al. 2009). Overall, Rhizopus spp. and Mucor spp. are considered the most prevalent causal agents of mucormycosis.

\section{Host Factors in Mucormycosis}

Diabetes mellitus is one of the major risk factors, affecting $36 \%-88 \%$ of all patients with mucormycosis (Joshi et al. 1999; Nithyanandam et al. 2003; Roden et al. 2005). Although a hyperglycemic state itself can be a predisposing factor for disease development (Helderman et al. 1974; Nithyanandam et al. 2003), Mucorales infections are particularly prevalent and fulminant in connection with diabetic ketoacidosis (DKA) or other forms of acidosis (Artis et al. 1982; Nithyanandam et al. 2003). During DKA, the concentration of ketones in the patient's blood increases, leading to acidification. The decrease in $\mathrm{pH}$ increases the availability of free iron, an essential growth factor for $\mathrm{Mu}$ corales. Indeed, Rhizopus species exhibit poor growth in normal iron-deprived serum but enhanced growth under elevated iron levels in vitro (Artis et al. 1982; Boelaert et al. 1993). In normal human serum, iron is bound to carrier proteins (e.g., transferrin, ferrin, or lactoferrin) to limit toxic effects while at the same time functioning as a host defense mechanism by iron deprivation (nutritional immunity) (Weinberg 1974; Howard 1999). During acidosis the binding affinity of the iron-binding glycoprotein transferrin is reduced, leading to the release of iron into the bloodstream (Ibrahim et al. 2008d). The loss of the growth-inhibitory function of iron-overloaded serum can be rescued with the iron chelators deferasirox and deferiprone (Ibrahim et al. 2006, 2007).
However, treatment with the iron-chelating agent deferoxamine in dialysis patients or repeated blood transfusions in bone marrow transplant patients with myelodysplastic syndrome can also lead to iron overload and highly fatal $(\sim 80 \%)$ mucormycosis (Boelaert et al. 1988, 1989, 1991; Maertens et al. 1999). Deferoxamine-treated guinea pigs challenged with Rhizopus spp. show increased susceptibility and reduced survival (Van Cutsem and Boelaert 1989; Boelaert et al. 1993). Interestingly, deferoxamine acts in the context of Rhizopus infection as a siderophore and transfers iron molecules from transferrin to the fungus by receptor-mediated interaction, thus supporting fungal growth (Boelaert et al. 1993, 1994; de Locht et al. 1994).

Furthermore, individuals with suppressed immunity (e.g., because of transplantation, malignancies, HIV, steroids, or neutropenia) are at increased risk of developing mucormycosis, with high mortality rates of $68 \%-100 \%$ (Roden et al. 2005; Chayakulkeeree et al. 2006). These patients often present with defects in innate immunity, particularly of phagocytic effector cell functions. For example, $\sim 15 \%$ of patients in this group who develop mucormycosis have severe neutropenia (Chayakulkeeree et al. 2006; Ibrahim et al. 2012). In addition, impaired macrophage or neutrophil function because of corticosteroid therapy might also significantly increase susceptibility to Mucorales infections (Ribes et al. 2000).

In healthy individuals, phagocytes induce differential immune responses depending on the fungal morphological structure. Murine bronchoalveolar macrophages inhibit germination of Rhizopus oryzae spores and thus prevent the formation of invasive hyphal forms (Waldorf et al. 1984a; Waldorf 1989; Jorens et al. 1995). Although macrophages are unable to kill fungal spores, macrophages, monocytes, and human neutrophils can damage and kill fungal hyphae without prior phagocytic uptake by means of oxidative stress and cationic peptides (Chinn and Diamond 1982; Diamond and Clark 1982; Diamond et al. 1982; Levitz et al. 1986; Waldorf 1989). Interestingly, fungal morphology also affects the chemotactic potential of $R$. 
oryzae on neutrophils. Although inactive spores do not induce neutrophil migration, active spores and hyphae present a potent chemotactic signal (Waldorf and Diamond 1985). After encountering $R$. oryzae hyphae, human polymorphonuclear neutrophils activate the expression of Toll-like receptor 2 and NF- $\mathrm{B}$ pathwayrelated genes (Chamilos et al. 2008b). Additionally, Dectin-1-dependent activation of interleukin 23 production by human dendritic cells induces proinflammatory Th17 responses (Chamilos et al. 2010).

In contrast, macrophages from diabetic or corticosteroid-treated mice fail to inhibit spore germination (Waldorf et al. 1984a,b). Neutrophils from diabetic patients with hyperglycemia and DKA retain the ability to damage fungal hyphae but show reduced responses to $R$. oryzae chemotactic factors (Chinn and Diamond 1982). This might interrupt downstream signaling and the activation of appropriate downstream cytokine responses.

Intact skin as a mechanical barrier for entry of Mucorales spores is an important defense mechanism against infections. The breakdown of the skin barrier by burns or local trauma injuries has been recognized as a common risk factor for developing mucormycosis. Particularly in recent years, clusters of infections with unusual Mucorales members (e.g., Apophysomyces spp. and Saksenaea spp.) have been identified in the context of environmental disasters such as the Joplin, Missouri tornado in 2011 (Etienne et al. 2012; Neblett Fanfair et al. 2012) and combat-related trauma (Evriviades et al. 2011; Warkentien et al. 2012). In these settings, injury often occurs as a result of extreme natural forces or explosive blasts resulting in deepseated tissue implantation of Mucorales spores from environmental sources. Additionally, nosocomial Mucorales infections have been reported in relation to surgical wound dressings (Gartenberg et al. 1978; Mead et al. 1979).

Other risk factors for mucormycosis include intravenous drug abuse, malnutrition, premature birth, and long-term application of the broad-spectrum antifungal voriconazole (Chayakulkeeree et al. 2006). Mucorales are resistant to voriconazole (Dannaoui et al. 2003) and have repeatedly been implicated in breakthrough infections in patients under prophylatic voriconazole treatment (Kontoyiannis et al. 2000, 2005; Imhof et al. 2004; Marty et al. 2004; Siwek et al. 2004; Roden et al. 2005; Trifilio et al. 2007). R. oryzae preexposure to voriconazole significantly decreased survival rates in Drosophila and murine infection models of mucormycosis. Mice infected with pretreated $R$. oryzae showed higher fungal burdens in the lungs, increased angioinvasion, enhanced inflammation, and pronounced tissue damage (Lamaris et al. 2009). However, the mechanism by which voriconazole elevates $R$. oryzae virulence is currently not understood.

\section{Host-Pathogen Interactions in Mucormycosis}

Mucorales-host interactions during infection are characterized by severe angioinvasion with vessel thrombosis and necrosis (Ibrahim et al. 2005b, 2012; Ben-Ami et al. 2009). Necrotic tissue can restrict the access of phagocytic effector cells or antifungals to infected areas, likely prohibiting fungal clearing and contributing to the organism's hematogenous dissemination via penetration of endothelial cells and the extracellular matrix of blood vessels (Ibrahim et al. 2012). R. oryzae ungerminated spores, but not germinated spores or hyphae, attach to the matrix proteins laminin and type IV collagen in vitro (Bouchara et al. 1996). However, R. oryzae spores and germ tubes can adhere to human umbilical vein endothelial cells and cause cell damage by a phagocytosis-dependent mechanism (Ibrahim et al. 2005b). Strikingly, cell damage does not depend on infection with viable R. oryzae spores (Ibrahim et al. 2005b), which must be considered in clinical practice. The glucose-regulated protein GRP78, a member of the Hsp70 chaperone family, was identified as the receptor for invasion and damage of endothelial cells (Liu et al. 2010). Hyperglycemia and elevated iron concentration, conditions mimicking DKA, increase GRP78 expression and R. oryzae uptake by and subsequent damage of endothelial cells (Liu et al. 2010). Additionally, DKA mice express more GRP78 in target organs than normal mice. Recently, the Mucorales li- 
gand that binds to GRP78 was identified as $\mathrm{Cot} H$, a cell surface protein unique to Mucorales (Gebremariam et al. 2014). Collectively, these findings likely explain the susceptibility of diabetic patients and individuals with iron overload to mucormycosis. Anti-GRP78 or anti-CotH antibodies were protective in $R$. oryzae-infected DKA mice (Liu et al. 2010; Gebremariam et al. 2014) and might offer a new therapeutic strategy for disease management.

The size of spores is also known to contribute to virulence ( $\mathrm{Li}$ et al. 2011). In a heterologous wax moth larva mucormycosis model, large multinucleate spores exhibit higher virulence compared with small mononucleate spores, which is likely caused by the ability of larger spores to germinate more rapidly than smaller spores. This is further supported by the observation that larger spores can germinate inside macrophages, whereas macrophages can contain smaller spores on phagocytosis. These findings coincide with examples of fungal cell size dimorphism contributing to virulence. For example, the human-pathogenic basidiomycete Cryptococcus neoformans often produces mononucleate but polyploid giant/titan cells, which are less susceptible to the host immune system (Okagaki et al. 2010; Zaragoza et al. 2010). In addition, Coccidioides immitis, an ascomycetous human pathogen, generates significantly enlarged multinucleate spherules that enable the fungus to escape the host immune system (Huppert et al. 1982; Hung et al. 2007).

\section{Treatment of Mucormycosis}

Four factors are critical to eradicate mucormycosis, including the following: (1) early diagnosis; (2) reversal of the underlying predisposing factors, if possible; (3) surgical debridement when possible; and (4) appropriate antifungal therapy. Early diagnosis is critical because small, focal lesions can often be surgically excised before they progress to involve critical structures or disseminate. Moreover, early initiation of polyene therapy within $5 \mathrm{~d}$ of diagnosis has been associated with improvement in survival (Chamilos et al. 2008a). Equally important is the correction or control of the mucormyco- sis-predisposing factors. For example, in DKA patients, hyperglycemia and acidemia should be corrected. Similarly, stopping or reducing immunosuppressive therapy, particularly corticosteroids, should be strongly considered when the diagnosis of mucormycosis is made. Finally, iron administration to patients with active mucormycosis (e.g., treatment with deferoxamine) should be avoided, as iron exacerbates infection in animal models (Abe et al. 1990; Ibrahim et al. 2007). Iron can also be liberated during blood transfusion as a result of hemolysis, so a conservative approach to red blood cell transfusions is advisable.

Blood vessel thrombosis and resulting tissue necrosis are a hallmark of mucormycosis and can result in poor penetration of antifungal agents to the site of infection. Therefore, surgical debridement of the infected and necrotic tissue should be performed on an urgent basis to improve outcome. Among patients with pulmonary mucormycosis, surgical treatment plus antifungal therapy greatly improves outcome compared with the use of antifungal therapy alone (Tedder et al. 1994). Moreover, surgery was found to be an independent variable predicting a favorable outcome in patients with mucormycosis (Roden et al. 2005). Retrospective data support the use of intraoperative frozen sections to delineate the margins of infected tissues, with sparing of tissues lacking evidence of infection (Langford et al. 1997).

\section{Antifungal Monotherapy}

Primary antifungal therapy for mucormycosis should be based on a polyene antifungal agent. Amphotericin B deoxycholate (AmB) is the only antifungal agent approved for the treatment of mucormycosis (Kwon-Chung and Bennett 1992; Spellberg et al. 2005; Sugar 2005). Mucorales are relatively resistant to $\mathrm{AmB}$, which necessitates the administration of high doses of the drug that are often associated with nephrotoxicity. However, lipid formulations of AmB can be administered at higher doses because they are significantly less nephrotoxic, which makes them likely to be more effective than AmB (Walsh et al. 1999; Ibrahim et al. 2003; Reed 
et al. 2008). Liposomal amphotericin B (LAmB) is preferred to amphotericin B lipid complex for infections with central nervous system involvement based on retrospective survival data (Gleissner et al. 2004) and evidence of superior brain penetration in animal models (Groll et al. 2000; Ibrahim et al. 2008c). In support of these findings, a retrospective series in patients with rhino-orbital-cerebral mucormycosis receiving amphotericin B lipid complex as primary therapy found that these patients had inferior outcomes compared with patients receiving either AmB or LAmB (Reed et al. 2008). There is no clear advantage of either agent for non-central nervous system infections.

Although itraconazole is considered to be the first marketed azole drug with some in vitro activity against Lichtheimia (Sun et al. 2002), its role in managing mucormycosis is limited because of a lack of activity against Rhizopus spp., the most common pathogens isolated from clinical cases. Fluconazole and the second-generation broad-spectrum antifungals triazole and voriconazole are not active against $\mathrm{Mu}$ corales in vitro (Sun et al. 2002). As mentioned above, the prophylactic and therapeutic use of voriconazole in transplant patients has been associated with breakthrough-disseminated mucormycosis (Blin et al. 2004; Imhof et al. 2004; Kobayashi et al. 2004; Marty et al. 2004; Kontoyiannis et al. 2005; Oren 2005). In fact, a recent study showed that in vitro pretreatment of Mucorales with voriconazole, $\mathrm{AmB}$, or caspofungin acetate increased the virulence of these organisms in murine and Drosophila models of mucormycosis (Lamaris et al. 2009). In contrast, posaconazole is the only Food and Drug Administration-approved azole with broad in vitro activity against Mucorales (Dannaoui et al. 2003; Spreghini et al. 2010). However, posaconazole is efficaciously inferior to $\mathrm{AmB}$ for the treatment of murine mucormycosis and is not superior to placebo for the treatment of murine infection with $R$. oryzae (Rodriguez et al. 2008; Ibrahim et al. 2009; Luo et al. 2013b). Similar results were reported for mice infected with Mucor circinelloides (Salas et al. 2012). This could be a result of unfavorable pharmacokinetic/pharmacodynamic data that have raised concerns about the reliability of achieving adequate in vivo levels of orally administered posaconazole (Ullmann et al. 2006; Krishna et al. $2007 a, b, c)$. Consequently, posaconazole monotherapy cannot currently be recommended as primary treatment of mucormycosis. In contrast, available clinical data from open-label salvage studies suggest that posaconazole is a reasonable option for patients with mucormycosis who are refractory to or intolerant of polyenes (Greenberg et al. 2006; van Burik et al. 2006). Posaconazole is also commonly used as "stepdown" therapy among stable patients who have initially responded to a polyene; however, no prospective studies have explored this therapeutic approach. Recent data also demonstrated activity of an investigational azole, isavuconazole, against Mucorales in vitro (Guinea et al. 2008; Verweij et al. 2009) and in vivo (Luo et al. 2013a). These data suggest that isavuconazole is likely to play a role in managing patients with mucormycosis in the future.

Finally, $R$. oryzae has a 1,3 - $\beta$-glucan synthase, the target enzyme for echinocandins (Ma et al. 2009), and this enzyme can be inhibited by these agents (Ibrahim et al. 2005a). However, this class of antifungal agents has minimal activity against agents of mucormycosis when tested in vitro or in experimental mucormycosis (Diekema et al. 2003; EspinelIngroff 2003; Ibrahim et al. 2005a).

\section{Antifungal Combination Therapy}

In murine experimental mucormycosis, polyene-posaconazole combination therapy is not superior to polyene monotherapy for mucormycosis in mice (Ibrahim et al. 2009), and no comparative data are available for combination therapy in humans. Therefore, there is no basis for recommending polyene-posaconazole combination therapy. Despite the modest activity of echinocandins against Mucorales (Diekema et al. 2003; Espinel-Ingroff 2003; Ibrahim et al. 2005a), the use of this group of antifungals in combination with lipid formulations of AmB improves the outcome of mucormycosis in mice (Spellberg et al. 2005; Ibrahim et al. 2008b). Human data also support the use 
of lipid-formulation AmB and echinocandins, albeit from a small retrospective study. Combination therapy with lipid formulations of $\mathrm{AmB}$ plus caspofungin was associated with significantly improved outcomes for rhino-orbital-cerebral mucormycosis in diabetic patients compared with polyene monotherapy (Reed et al. 2008). Because the data are very limited, further clinical studies are necessary to determine the usefulness of echinocandin combination therapy in patients with mucormycosis. Echinocandins should be administered at standard, Food and Drug Administration-approved doses, because dose escalation results in paradoxical loss of efficacy in preclinical models (Ibrahim et al. 2005a, 2008a).

\section{Iron Chelation Therapy and Other Novel Approaches}

Unlike deferoxamine, which predisposes patients to mucormycosis via a xenosiderophore-mediated iron supply mechanism (Boelaert et al. 1993), the iron chelator deferasirox is fungicidal for clinical isolates of Mucorales (Ibrahim et al. 2007). In DKA mice with disseminated mucormycosis, combination deferasirox-LAmB therapy resulted in synergistic improvement of survival rates and reduced fungal burden in the brain (Ibrahim et al. 2007). Based on these animal data, deferasirox was used successfully as salvage therapy in several patients with mucormycosis, including rhino-orbitalcerebral mucormycosis (Spellberg et al. 2009). Unfortunately, a randomized, double-blind, phase 2 safety clinical trial of adjunctive deferasirox therapy (plus LAmB) found excess mortality in the patients treated with deferasirox (Spellberg et al. 2012). However, patients in the deferasirox-LAmB arm were more likely than placebo patients to have active malignancy, neutropenia, or corticosteroid therapy and less likely to have received additional antifungals, making the results of this pilot trial less conclusive (Donnelly and Lahav 2012). The negative result of the phase 2 study came despite the continuing anecdotal success of the use of deferasirox as an adjunct therapy against mucormycosis (Soman et al. 2012; Ribeiro et al. 2013).
Given the rarity of the disease and the negative outcome from the phase 2 randomized clinical trial, a large phase 3 trial to elucidate the role of iron chelators in treating mucormycosis will be difficult to conduct. Alternatively, we believe that patients with a disease as fatal as mucormycosis would opt for an experimental treatment that might work if they are honestly informed of the risks and benefits.

Some case reports have suggested a successful outcome in managing mucormycosis with hyperbaric oxygen as an adjunct therapy. Hyperbaric oxygen might be useful for treating mucormycosis in conjunction with standard therapy because higher oxygen pressure improves the killing ability of neutrophils (Couch et al. 1988). Additionally, high oxygen pressure inhibits the germination of fungal spores and growth of mycelia in vitro (Robb 1966). Similarly, case reports have described survival of patients with mucormycosis treated with adjunct recombinant granulocyte colony-stimulating factor and granulocyte macrophage colonystimulating factor or with recombinant interferon- $\gamma$ in conjunction with lipid formulations of AmB (Gonzalez et al. 1997; Kullberg and Anaissie 1998; Ma et al. 2001; Mastroianni 2004; Abzug and Walsh 2004). Granulocyte colony-stimulating factor-mobilized granulocyte transfusions have been increasingly used for refractory mycoses, including mucormycosis (Slavin et al. 2002; Grigull et al. 2006).

In pathogenic fungi, the $\mathrm{Ca}^{2+} /$ calmodulindependent serine/threonine phosphatase calcineurin is involved in morphogenesis and virulence and is a promising target for antifungal drugs (reviewed in Chen et al. 2010). The calcineurin pathway is conserved throughout eukaryotes. Calcineurin consists of two subunits: the catalytic A subunit, which has phophatase activity; and the regulatory $B$ subunit, which binds to the A subunit for activation of the complex. The calcineurin inhibitors FK506 and cyclosporine A synergistically inhibit the growth of Mucorales in combination with other antifungal drugs (Dannaoui et al. 2009; Narreddy et al. 2010; Thakur and Revankar 2011). Efficacious outcomes were observed for combination therapy with posaconazole and FK506 in both 
L. Mendoza et al.

Drosophila and murine cutaneous mucormycosis model systems (Lewis et al. 2013). Another study found that FK506 treatment enforces M. circinelloides to grow as its less virulent yeast form, rather than its invasive hyphal form (Lee et al. 2013). In addition, when compared with other immunosuppressants, FK506 treatment results in lower rates of mucormycosis among solid organ transplant patients, which further suggests that calcineurin inhibitors may control mucormycosis (Singh et al. 2009).

\section{Genomes of Mucorales-Characteristics of Mucoralean Genomes: Rhizopus, Mucor, and Lichtheimia (ex Absidia)}

Members of the Mucorales, the most prominent order of the fungi formerly described as Zygomycota, belong to the one of the most ancient terrestrial fungal lineages. Morphological traits preserved in amber resemble those observed today, indicating their evolutionary success (Speranza et al. 2010). Calculations of the divergence time of the zygomycetes (here used colloquially for zygosporic fungi; formerly termed Zygomycota) from the other fungal lineages using molecular clock estimates suggest the first occurrence of zygomycetous fungi on Earth in the Precambrian era, $\sim 1200-1400$ million years ago (Heckman et al. 2001; Blair 2009). More conservative estimations place their divergence at $\sim 800$ million years ago (Fig. 2) (Berbee and Taylor 2001). Thus, zygomycetous fungi and their most prevalent order, the Mucorales, were certainly important elements of ancient terrestrial ecosystems (Krings et al. 2013). During this long evolutionary history, they became ubiquitously distributed worldwide and evolved various modes of nutrition ranging from saprobic to facultatively parasitic in fungi and plants and occasionally endophytic in plants, eventually becoming an important group of opportunistic, systemic infection-causing pathogens of humans.

The thalli of the Mucorales are composed of substrate mycelium, which is usually extremely robust and develops vigorously growing aerial hyphae. Fertile hyphae are septate (microporic) and never doliporic (which is exclusively found in higher fungi) at maturity. Asexual reproduction occurs by spores formed in sporocarps, which are multispored sporangia or uni/fewspored sporangiola that develop in soil or on organic material above ground (Benjamin 1979; Benny et al. 2001). Sporangia develop a visible, variously shaped columella (a bulbous vesicle at the sporangiophore apex), which always protrudes into the sporangium. The existence of a visible, well-developed columella in multispored sporangia counts as the trademark of the Mucorales as a phylogenetically coherent (monophyletic) order (Fig. 1) (reviewed in Voigt 2012; for a phylogenetic overview, see Hoffmann et al. 2013).

Because of the recent appearance of genomic sequences from various zygomycetous fungi, a comprehensive genome analysis is in progress from the zygomycetes (Entomophthorales, Mucorales, and Mortierellales) (Table 1). Large-scale genome projects (e.g., Fungal Genomics Program, 1000 Fungal Genomes Project [1KFG], and Mycocosm performed by the U.S. Department of Energy's Joint Genome Institute [DOE-JGI], as well as the Fungal Genome Initiative and the Origins of Multicellularity Project, which are both carried out at the Broad Institute of Massachusetts Institute of Technology and Harvard University) produced a total of 10 genomes of the mucoralean fungi; among those, seven are from human-pathogenic opportunists. The genomes from $M$. circinelloides f. lusitanicus strain CBS277.49 (GenBank accession number of the genome project: PRJNA46717), Phycomyces blakesleeanus strain NRRL1555 [(-) mating type; PRJNA61391], Rhizopus delemar (ex R. oryzae type II strains, which produce fumaric-malic acid) strain RA99-880 (PRJNA13066), and Lichtheimia corymbifera strain JMRC:FSU:9682 (PRJEB3978) are completed (finalized or permanent draft; Table 2).

Rhizopus: The Most Important Genus within the Human-Pathogenic Mucorales

The genus Rhizopus is the type genus of the family Rhizopodaceae K. Schum. 1984 and develops sporangiophores forming an umbel. Each branch forms a secondary umbel that 


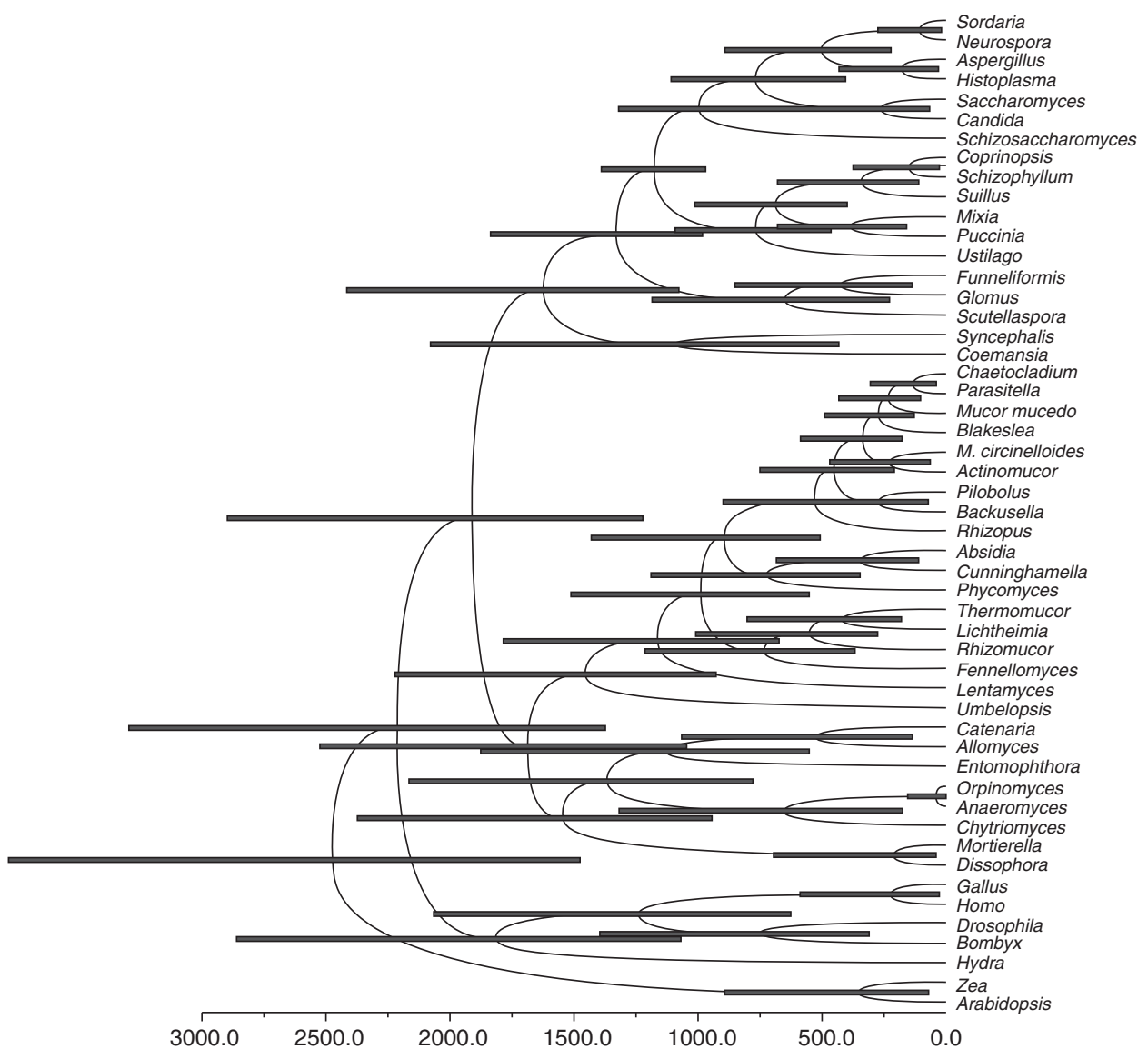

Figure 2. Timing of fungal divergences using BEAUTi and BEAST assuming a Basidiomycota-Ascomycota split $1200 \pm 108$ million years ago (Heckman et al. 2001). Node bars indicate $95 \%$ highest posterior density intervals of node heights. Calculation of diverging times was performed using BEAUTi v1.7.1 and BEAST v1.6.2 (Drummond et al. 2012). A reduced 18 S rDNA alignment (51 taxa, 1195 characters) was used as input for BEAUTi. BEAUTi was run choosing the substitution model GTR with empirical base frequencies, GTR + I as site heterogeneity model, and six $\gamma$ categories. The clock model was set to lognormal relaxed clock, estimate turned on. Calibration was performed by assuming a split of Ascomycota and Basidiomycota occurring $1208 \pm 108$ million years ago with normal distribution (Heckman et al. 2001). The generated xml file was run in BEAST over the CIPRES portal (www.phylo.org). Sampled reasonable trees were summarized with the TreeAnnotater from the BEAST package.

branches dichotomously, one branch terminating in a sporangium and the other in sterile spines, building the rhizoids, which are characteristic for the genus and abundant among members of the genus (reviewed in Voigt 2012). Species of the genus Rhizopus are saprobes in soil and have importance as biotransforming and food-fermenting agents. Additionally, they can cause disease in plants, animals, and humans. They are predominantly thermo- tolerant, rhizoid-forming, multispored-sporangiate Mucor-like fungi. Molecular phylogenetic analyses revealed a split into three clades: a thermophilic Rhizopus microsporus group (growth up to $45^{\circ} \mathrm{C}$ ), a subthermotolerant Amylomyces $-R$. oryzae species complex group (growth at $37^{\circ} \mathrm{C}-40^{\circ} \mathrm{C}$ ), and a mesophilic Rhizopus stolonifer group (growth below $37^{\circ} \mathrm{C}$ ). The subthermophilic $R$. oryzae is the primary cause of mucormycosis, hence, a logical initiation point 
L. Mendoza et al.

Table 1. Zygomycetous genome sequencing projects (as of December 30, 2013)

\begin{tabular}{lcccc}
\hline & \multicolumn{3}{c}{ Complete } & \\
\cline { 2 - 3 } Order & Finished & Permanent draft & Incomplete $^{\mathrm{a}}$ & Targeted $^{\mathrm{a}}$ \\
\hline Entomophthorales & 1 & 0 & 4 & 0 \\
Mortierellales & 0 & 1 & 2 & 0 \\
Mucorales & 4 & 0 & 17 & 0 \\
\hline
\end{tabular}

Source: Entompohthorales: GOLD (Genomes Online Database) at www.genomesonline.org; Mucorales and Mortierellales: NCBI (National Center for Biotechnology Information) at www.ncbi.nlm.nih.gov/genome.

${ }^{\mathrm{a}}$ Only whole-genome sequencing projects.

for the first genome project within the Mucorales. The genome sequence of $R$. delemar strain 99-880 (also termed RA 99-880), isolated from a fatal case of mucormycosis, was determined by the Broad Institute (PRJNA13066) (Ma et al. 2009). This strain was isolated in 1999 from a brain abscess of a diabetic patient who developed fatal rhinocerebral mucormycosis. The highly repetitive $45.3-\mathrm{Mb}$ genome assembly contains abundant transposable elements, comprising $\sim 20 \%$ of the genome. The original protein prediction reported by Ma et al. comprised 13,895 protein-coding genes, which was verified to encode a total of 17,459 proteins (based on the Fungal Genome Collection of the University of Nebraska, Lincoln, School of Biological Sciences and Center for Plant Science Innovation at em-x8.unl.edu/ canderson/FungalGenome Collection). The order and genomic arrangement of the duplicated gene pairs and their common phylogenetic origin provided evidence for an ancestral whole-genome duplication event (Ma et al. 2009). The whole-genome duplication resulted in the duplication of nearly all subunits of the protein complexes associated with the respiratory electron transport chains, V-ATPase, and ubiquitin-proteasome systems, as well as the expansion of multiple gene families related to cell growth and signal transduction and secreted aspartic protease and subtilase protein families, which are known fungal virulence factors. The duplication of the ergosterol biosynthetic pathway (e.g., lanosterol 14 $\alpha$-demethylase [Erg11], the major azole target) was postulated to contribute to the variable responses of $R$. oryzae to different azole drugs, including voriconazole and posaconazole (Vitale et al. 2012). Expanded families of cell-wall synthesis enzymes, which are essential for fungal cell integrity and are absent in mammalian hosts, reveal potential targets for novel and $R$. oryzaespecific diagnostic and therapeutic treatments (Ma et al. 2009). R. oryzae comprises a morphologically and physiologically heterogenous species complex encompassing the sibling species $R$. oryzae sensu stricto and $R$. delemar. Phylogenetic analyses of genes encoding rDNA, internal transcribed spacer (ITS), lactate dehydrogenase $B$, actin, translation elongation factor- $1 \alpha$, and genome-wide amplified fragment length polymorphisms resolved the same two exclusive clusters, corresponding with the production of organic acid as an effective taxonomic character-

Table 2. Completed genome sequencing projects from the Mucorales and the Entomophthorales, the zygomycetous orders with potential to cause mycoses in humans (as of December 30, 2013)

\begin{tabular}{lccc}
\hline & \multicolumn{3}{c}{ Finished } \\
\cline { 2 - 4 } & $\begin{array}{c}\text { GOLD- } \\
\text { ID }\end{array}$ & $\begin{array}{c}\text { NCBI } \\
\text { accession }\end{array}$ & $\begin{array}{c}\text { NCBI- } \\
\text { ID }^{\mathrm{a}}\end{array}$ \\
\hline Mucorales & Gi01096 & PRJNA61391 & 61391 \\
& Gi00506 & PRJNA13066 & 13066 \\
& - & PRJNA46717 & 46717 \\
Entomophthorales & - & PRJEB3978 & - \\
& - & C. coronatus $^{\mathrm{c}}$ & - \\
\hline
\end{tabular}

Source: GOLD at www.genomesonline.org, NCBI at www.ncbi.nlm.nih.gov/genome, and ENA (European Nucleotide Archive) at www.ebi.ac.uk/ena.

${ }^{a}$ Numbers for the NCBI-ID refer to NCBI project identification numbers (IDs).

${ }^{\mathrm{b}}$ ENA submission of the genome of the mucoralean fungus Lichtheimia corymbifera JMRC:FSU:9682 to be released in 2014.

${ }^{c}$ The genome of the entomophthoralen fungus Conidiobolus coronatus JMRC:FSU4392 to be released in 2014 (unpublished and not yet submitted). 
HFPs of Mucorales and Entomophthorales

istic. These studies grouped the species complex into two sibling species: $R$. oryzae sensu stricto (also known as R. arrhizus) and R. delemar, correlating with lactic acid and fumaric-malic acid production, respectively (Abe et al. 2007). Reclassification of strains in the fumaric-malic acid group as $R$. delemar, and, therefore, reclassification of the genome strain $R$. oryzae 99-880 into $R$. delemar, was proposed (Gryganskyi et al. 2010). More genome projects on $R$. oryzae were initiated on strains 99-892 (PRJNA186020), B7407 (PRJNA184879), HUMC 02 (PRJNA 186018), NRRL13440 (PRJNA186013), and NRRL21396 (PRJNA186015), with the latter two being classified as type 1. In addition to the genome projects on the $R$. delemar $-R$. oryzae species complex representing the subthermophilic Rhizopus group, further genome projects were initiated on two strains of $R$. $m i$ crosporus (ATCC52813 and CCTCCM201021) and R. stolonifer strain B9770 (PRJNA184886), representing the thermophilic and the mesophilic groups, respectively (classification in accordance to Voigt 2012). R. microsporus is traditionally used for brewing alcoholic beverages and fermented foods in China (Wang et al. 2013) but is also an important causative agent of mucormycosis (de Hoog et al. 2000). The 45,666,236-bp (ca. 45.7-Mb) draft genome sequence of $R$. microsporus var. chinensis CCT CCM201021 (PRJNA179339), isolated from the leaven Daqu, was determined, annotated, and released in February 2013 (Wang et al. 2013). The genome of $R$. microsporus var. microsporus ATCC52813 (PRJNA205957) was released in August 2013 as part of the 1 KFG project. With the exception of the genome from $R$. delemar strain 99-880, all other genomes of Rhizopus spp. are incomplete. The size and GC content of the Rhizopus genomes are always around $45 \mathrm{Mb}$ and $36.9 \%$, respectively.

M. circinelloides: Genome Initiatives of the Second Most Common Causative Agent of Emerging Mucormycosis

M. circinelloides, the type genus of the order Mucorales, and belonging to the family Mucoraceae Dumort. 1822, develops as any other spe- cies within the genus Mucor with aerial hyphae, which sense and grow toward light (positively phototropic). M. circinelloides is ubiquitously distributed and saprobic in soil. Its dispersal occurs through the air, soil, and food. Similar to other human-pathogenic Mucorales, M. circinelloides is an emerging opportunistic pathogen that causes deep and systemic mucormycosis in immunocompromised humans. The spore size is linked to virulence, and the plasticity of the sex locus and adaptations in pathogenicity have occurred during speciation of the M. circinelloides complex (Li et al. 2011). M. circinelloides exhibits hyphal growth in aerobic conditions but switches to multibudded yeast growth under anaerobic or high- $\mathrm{CO}_{2}$ conditions. The calcineurin pathway orchestrates the yeast-hyphal and spore size dimorphic transitions that contribute to virulence of this common zygomycete fungal pathogen (Lee et al. 2013). The genome of $M$. circinelloides $\mathrm{f}$. lusitanicus CBS277.49 (PRJNA46717) was published as a first draft in March 2009 and as a second assembly form in December 2009. In total, 10,930 and 11,719 genes were structurally and functionally annotated in the first and second versions of the draft assembly, respectively, and the annotation releases have a genome size of $36.5 \mathrm{Mb}$ ( genome.jgi.doe.gov/Mucci2/Mucci2.info.html). The first version of the genome assembly from M. circinelloides $\mathrm{f}$. circinelloides strain $1006 \mathrm{PhL}$ was released in April 2013 by the Broad Institute (PRJNA172437). The genome size is $36.55 \mathrm{Mb}$, and the GC content is $39.5 \%$. Of a total of 12,410 predicted genes, 12,227 were functionally annotated to proteins (based on information from www.ncbi.nlm.nih.gov/genome/?term = Mucor + circinelloides + f. + circinelloides).

\section{Lichtheimia: Non-Rhizopus/Mucor-Like Human-Pathogenic Opportunists}

The genus Lichtheimia is the type genus of the family Lichtheimiaceae K. Hoffm., G. Walther \& K. Voigt (Hoffmann et al. 2009). Colonies of Lichtheimia rapidly grow at temperatures between $37^{\circ} \mathrm{C}$ and $42^{\circ} \mathrm{C}$ and are predominantly thermotolerant until a maximum of $55^{\circ} \mathrm{C}$. The hyphae of the substrate mycelia form char- 
L. Mendoza et al.

acteristic tree-like structures among the growth front and giant cells, which are never found in any of the other pyriform sporangiate absidiaceous fungi, formerly classified in the genus Absidia (Hoffmann et al. 2009). Lichtheimia spp. are ubiquitously distributed and are saprobic decomposers in soil and decaying organic matter (e.g., compost, silage, and fermented food), but they have also become of increasing importance as causative opportunistic agents of systemic mycoses in humans. They represent the second and third most common cause of mucormycosis in Europe and worldwide, respectively (Roden et al. 2005; Skiada et al. 2011; Lanternier et al. 2012a,b). The genus Lichtheimia encompasses six thermotolerant species: $L$. corymbifera, L. ramosa, L. ornata, L. hyalospora, L. sphaerocystis (Alastruey-Izquierdo et al. 2010), and L. brasiliensis (Santiago et al. 2014). The former three are known to be clinically relevant (Schrödl et al. 2012). Pulmonary Lichtheimia infections following solid organ transplantation seem to be associated with a higher risk of developing disseminated disease (Sun et al. 2009). To gain insight into the genomic differences between these groups of pathogens, the type strain of L. corymbifera (JMRC:FSU:9682 $=$ CBS $429.75=$ ATCC46771) was sequenced and compared to published genomes of other fungi comprising several phyla. Comparative genomics studies on Lichtheimia reveal a large evolutionary distance to all fungal genomes published until now, providing evidence for the hypothesis that L. corymbifera has independently evolved its ability to infect humans by developing specific pathogenesis mechanisms (Schwartze et al. 2014). If these differences are reflected in the genome, the mechanism may be revealed through the analysis of the genome of the thermotolerant but not human-pathogenic species L. hyalospora, for which the first assembly version was released by DOE-JGI in the 1 KFG project in July 2013 (genome.jgi.doe. gov/Lichy1/Lichy1.home.html).

\section{Further Mucorales Genome Initiatives}

The genome (53.9 Mbp in size) of P. blakesleeanus NRRL1555 [(-) mating type; PRJNA
61391) was finished and released by DOE-JGI in September 2006 (first version) and March 2010 (second version). The latest version contains a total of 16,528 predicted proteins (Fungal Genome Collection of the University of $\mathrm{Ne}$ braska, Lincoln, School of Biological Sciences and Center for Plant Science Innovation at em-x8.unl.edu/ canderson/FungalGenome Collection/GenomeSummary). In addition to NRRL1555 [UBC2 (-)], a wide variety of strains, 20 in total [UBC21 (+), A893, A905, A909, B2, B16, C6, C21, C47, C68, C107 (+), C109, C110, C149, C307, L151, L153, L157, L161, and L163], are currently sequenced at the DOE-JGI (based on information in GOLD at www.genomesonline.org).

Within the 1KFG, the genomes of Backusella circina FSU941 (genome size of $48.65 \mathrm{Mb}$, genome.jgi.doe.gov/Baccil/Baccil.info.html) and Umbelopsis ramanniana (genome size of 23.08 Mb; genome.jgi-psf.org/Umbra1/Umb ral.home.html) were released in July and September 2013, respectively. Based on information in GOLD, a variety of genome projects on Rhizomucor spp. (R. miehei CBS182.67 [Gi17195] and R. pusillus CBS183.67 [Gi17196]) were initiated by the McGill University and Genome Quebec Innovation Centre. Both species play important roles in food fermentation as opportunistic human pathogens (de Hoog et al. 2000).

\section{ENTOMOPHTHORAMYCOSIS: THE ZOOPATHOGENIC FUNGI OF THE ENTOMOPHTHOROMYCOTA}

\section{General Characteristics and Brief Historical Review}

The mammalian-pathogenic species of the Entomophthoromycota comprise members in the genera Basidiobolus and Conidiobolus (McGinnis 1980; Khan et al. 2001; Kwon-Chung 2012). The species of these genera are the etiologic agents of entomophthoramycosis, an infection of humans and lower animals that is restricted to the subcutaneous tissues and rarely involves other organs (Fromentin and Ravisse 1977; McGinnis 1980). They are characterized by the production of a variety of spores in nature and in vitro, a property that has been used for 
the taxonomic separation of species, but in the past it has also fueled taxonomic controversies (Kwon-Chung 2012; Gryganskyi et al. 2013). The mammalian-pathogenic species within the Entomophthoromycota are characterized by the production of slow-growing tumoral-like masses in the infected tissues that in some cases remain indolent for years. The area most commonly affected by Conidiobolus species is the face (generally around the nose) (McGinnis 1980), whereas Basidiobolus species are frequently found on limbs, the intestinal tract, and rarely in other body areas.

The majority of the fungi causing entomophthoramycosis develop short or long, broad (ribbon-type), sparsely septated hyphae in the infected host tissues and produce different types of asexual spores in culture (McGinnis 1980; Kwon-Chung 2012). The sexual spores have also been found in recently isolated strains from clinical cases of the disease, but they are usually lost after several subcultures (KwonChung 2012). A typical feature of these pathogens in the infected host's tissues is the production of a red-colored reaction around the invading hyphae known as the Splendore-Hoeppli phenomenon (Kimura et al. 2011; Kwon-Chung 2012). Interestingly, this phenomenon has been also encountered in mammalian tissues infected by parasites (Miller and Campbell 1984; Kimura et al. 2011) and around the hyphae of the fungal-like mammalian-pathogenic oomycetes Pythium insidiosum and Lagenidium spp. (Miller and Campbell 1982; Mendoza and Vilela 2013). This phenomenon has previously been used to separate the genera Basidiobolus and Conidiobolus from other fungi in the absence of culture (Guarro et al. 1999; Gugnani 1999; Kwon-Chung 2012). However, this practice is inappropriate because the above-mentioned zoopathogenic oomycetes also develop a similar reaction in the tissues of their infected hosts (Mendoza and Vilela 2013).

Van Overeem reported the first known case of an infection caused by a member of the Entomophthoromycota in 1925 in Indonesia from a fistular ulcerated lesion on a horse limb. The second case occurred in humans and was also diagnosed in Indonesia (Kian Joe et al. 1956).
The investigators recovered a strain of Basidiobolus ranarum from two children with subcutaneous infection. Numerous other cases have been diagnosed since the initial report (McGinnis 1980). Disseminated and intestinal infections caused by Basidiobolus have been also reported (Gugnani 1999). Subcutaneous infections involving Conidiobolus coronatus were first observed in 1961 by Bridges et al. (1962) in four horses in Texas, and in humans 4 years later (Bras et al. 1965). However, the first case of human nasofacial involvement without culture was recorded by Blanché et al. in 1961. The first recorded cases of Conidiobolus incongruus in humans took place in 1970 (Gilbert et al. 1970), and the recovered organism was properly identified by King and Jong (1976). Conidiobolus lampragues was first recognized as an etiologic agent of entomophthoramycosis in a horse with subcutaneous infection (Humber et al. 1989) and more recently in sheep and humans (Vilela et al. 2010; Kimura et al. 2011).

\section{Systematic Position and Nomenclature}

Recent phylogenetic studies of fungi previously placed within the obsolete phylum Zygomycota (Kwon-Chung 2012) indicated that the zoopathogenic genera Basidiobolus and Conidioblous are now considered members of the newly created monophyletic phylum Entomophthoromycota (Gryganskyi et al. 2013). The Entomophthoromycota comprises three classes: Basidiobolomycetes (Basidiobolus spp.), Neozygitomycetes (Neozygitis spp.), and Entomophthoromycetes (Conidiobolus spp., Completoria spp., Entomophthora spp., and others). The proposed taxonomic and phylogenetic changes placed the genus Basidiobolus within the class Basidiobolomycetes, order Basidiobolales, family Basidiobolaceae (Humber et al. 1989; KwonChung 2012; Gryganskyi et al. 2013), whereas the genus Conidiobolus is placed within the class Entomophthoromycetes, order Entomophthorales, family Ancylistaceae (Gryganskyi et al. 2013). Under this new nomenclature, the old terminology-phycomycosis, rhinophycomycosis, zygomycosis, rhinozygomycosis, and others - used to name the diseases caused by 
L. Mendoza et al.

Basidiobolus and Conidiobolus species is no longer supported (Kwon-Chung 2012). However, the epithets "basidiobolomycosis," "conidiobolomycosis," and "rhinoconidiolomycosis" do not contradict the new classification and will probably remain in use.

Vilela et al. (2010) conducted the first phylogenetic analysis of the pathogenic Conidiobolus spp. using $18 \mathrm{~S}$ rDNA sequences, a study confirmed a few months later (de Paula et al. 2010). In their analysis, DNA sequences from three strains of $C$. coronatus clustered with Conidiobolus firmipilleus; in turn, this cluster was a sister group with strong bootstrap support to C. incongruus and Conidiobolus brefeldianus. C. lampragues clustered in a long branch to Conidiobolus osmodes, Conidiobolus pumilus, Conidiobolus rhysosporus, and Conidiobolus thromboides. B. ranarum was used as an outgroup in the analysis. This result suggests that $C$. coronatus and $C$. incongruus share more phylogenetic similarities with each other than with C. lampragues. Nie et al. (2012) and Jensen et al. (1998), using $18 \mathrm{~S}$ small-subunit rDNA and 28S rDNA sequences and additional Conidiobolus species, reported that $C$. coronatus formed a well-supported sister cluster to C. firmipilleus, a finding in agreement with previous studies (Vilela et al. 2010). Unfortunately, this phylogenetic study did not include more pathogenic species. Thus, a more comprehensive study including both saprophytic and zoopathogenic species is necessary to better understand this interesting group of pathogens in the Entomophthoromycota.

Based on allelic variation, recent genomic analysis of $B$. ranarum showed that the nuclear genome is probably diploid with a putative genome size of $700 \mathrm{Mb}$ (Henk and Fisher 2012). The study found also redundancy in its elongation factors overlapping the paralog EF- $1 \alpha$. The investigators speculate that genome duplication is an important feature favoring the preservation of overlapping genes in B. ranarum (Henk and Fisher 2012).

\section{Ecology and Epidemiology}

The ecological niche of the species in the phylum Entomophthoromycota has been studied in fungal infections in insects or in apparent association with amphibians and reptiles without active disease (Groff et al. 1991). The species in this phylum are commonly found in plant detritus, where they could associate with insects or mammals by producing forcibly ejected sticky conidia that attach to the cuticle of insects or to the skin of mammals. They are among the most aggressive pathogens of insects and invade the whole insect body; the infecting fungus then bursts through its exoskeleton and produces more sticky conidia at the ends of single sporangiophores (King 1983; Werner et al. 2012). Amphibians and reptiles could come in contact with these fungal species by ingesting infected or colonized insects; the fungi thus become part of the creature's intestinal flora. Few reports of amphibians affected by these species have been published (Groff et al. 1991). B. ranarum has been recovered from the intestinal content of frogs and lizards and from their dung (Drechsler 1956). C. coronatus and C. incongruus have been isolated from plant detritus and insects (King and Jong 1976; Jensen et al. 1998). C. incongruus was also found as a nosocomial agent from a case of systemic entomophthoramycosis (Walsh et al. 1994). C. lampragues has only been recovered so far from infected mammals, but it probably colonizes decaying vegetables and may also be present in soil of the areas of endemicity (de Paula et al. 2010; Vilela et al. 2010; Skiada et al. 2012).

Both Conidiobolus spp. and Basidiobolus spp. are thermophilic fungi. Thus, these species are more commonly found in tropical and subtropical humid areas. When conditions of high humidity, sunlight, and high temperatures exist, their single sticky conidia are ejected and then attach to the skin of passing insects or animals, including mammals. Entomophthoramycosis has been recorded in the subcutaneous and intestinal tissues of apparently healthy or immunocompromised hosts and less frequently has been found to cause systemic infections (McGinnis 1980; Kwon-Chung 2012). Thus, it is believed that the species of these fungi can only reach the subcutaneous tissue of their infected hosts through open skin or through small abrasions in the intestinal tract (McGinnis 
HFPs of Mucorales and Entomophthorales

1980). The infection has been more frequently reported in the tropical and subtropical areas of Asia, Africa, and the Americas (Martinson and Clark 1967; Londero et al. 1979; Kelly et al. 1980; Gugnani 1999).

Taxonomic Description of the Mammalian Pathogens Basidiobolus and Conidiobolus Species

\section{Basidiobolus spp.}

Since the introduction of the genus Basidiobolus by Eidam in 1886, the description of the zoopathogenic species in this genus has been always contentious. Eidam used the described strain $B$. ranarum as the type species for the genus; thus, it has priority over other epithets suggested later (Eidam 1886). Based on the production of zygospores and other characteristics, Eidam introduced two new species: B. ranarum (zygospores with undulating and smooth outer cell walls) and B. lacerate (smooth zygospores similar to those of $B$. ranarum). In the original description, Eidam noted that B. ranarum was the first saprophytic organism recovered from frog excrement, whereas $B$. lacerate was isolated in lizard excrement. This fact and differences in morphological features convinced Eidam that both isolates were unrelated, and thus he described them as different species. A study performed later by Levisohn and others on the two Basidiobolus species introduced by Eidam concluded that the appearance of the outer cell wall of the $B$. lacerate zygospores was identical to that of $B$. ranarum and, therefore, it "should bear the name B. ranarum" (Levisohn 1927; Fitzpatrick 1930; Drechsler 1956).

The Streptomyces-like odor and the capacity to grow at different temperatures was a feature first described by Drechsler in some strains of Basidiobolus spp., characteristics also used to separate Basidiobolus species (Drechsler 1953; Greer and Friedman 1966; McGinnis 1980). However, these physiological characteristics are variable among species, and some strains possess one or more of these features, making their identification more difficult (Gugnani 1999). In 1947, Drechsler introduced the species Basidiobolus haptosporus and described this particular strain as a smooth zygospore producer; reports of mammals affected by this species appeared in the 1980s (Vismer et al. 1980). In 1962 , Benjamin proposed another species, $\mathrm{Ba}$ sidiobolus microspores, based on the development of multiple sharp elongate "microspores" from globose conidia and stretched zygospores. B. microspores is the only species that can be properly differentiated from other species because of its unique broad base and fine elongate replicative "microspores" on top of primary conidia (Benjamin 1962).

The use of classical tools during the description of the strain isolated from the first human case caused by Basidiobolus spp. proved that traditional methodologies are inaccurate (Kian Joe et al. 1956; McGinnis 1980; Kwon-Chung 2012). Kian Joe et al. (1956) described undulated outer cell walls of zygospores, and thus the strain was identified as B. ranarum. However, some had challenged their observations because some figures were not clear, and the strain seems to display both undulated outer cell walls and mostly smooth outer cell walls of zygospores (McGinnis 1980). Drechsler studied the same strain and, based on the presence of smooth zygospores, determined (Drechsler 1956) that it was very similar to Basidiobolus meristosporus (Thasnakorn et al. 1969). Numerous studies on the original isolate from the first human cases of basidiobolomycosis had suggested that the species B. haptosporus (Drechsler 1947; Srinivasan and Thirumalachar 1965), Basidiobolus heterosporus (Srinivasan and Thirumalachar 1965), B. lacerate (Eidam 1886), B. meristosporus (Drechsler 1956), and similar species should be all treated as synonyms of B. ranarum (McGinnis 1980; Gugnani 1999). $B$. microsporus, on the other hand, can be properly separated from $B$. ranarum (Benjamin 1962).

The cell cycle of the family Basidiobolaceae is complex. Members of the family developed different types of phenotypic structures depending on their environmental conditions. They can also be readily recovered in culture from contaminated environmental sources as well as from clinical cases of basidiobolomycosis (Srinivasan and Thirumalachar 1965; Skiada 
L. Mendoza et al.

et al. 2012). The genus Basidiobolus is not a traditional pathogen of insects but some species can be easily recovered from the intestinal contents of amphibians and reptiles (Eidam 1886). Based on this fact, some have hypothesized that some species could affect insects or perhaps that insects only act as host carriers of Basidiobolus species, especially mites (Ingold 1934; Werner et al. 2012). The mechanism of conidium ejection is different from that of Conidiobolus (Ingold 1934; Yafetto et al. 2008). In Basidiobolus spp. (Fig. 3A), the formation of a uninucleate "ballistoconidium" on top of a simple conical columella is observed before ejection (Fig. 3Aa). At maturity, a subconidial vesicle develops that becomes turgid because of the pressure exerted by the accumulation of liquid within this region (Fig. 3Ab). Under appropriate environmental conditions (light, humidity, and others), the pressure results in weakness at the base of the elastic subconidial structure, which is forcibly ejected along with the conidium (Fig. 3Ac) (Dykstra 1994). The structure remains attached to the ejected conidium during the expulsion, but could be detached after landing (Ingold 1934; Yafetto et al. 2008). Ingold found that the distance that Basidiobolus conidia traveled was between 1 and $2 \mathrm{~cm}$ (Ingold 1934). Thus, the ejected primary conidia (see Basidiobolus conidia release below) could attach to mites, other invertebrates, and mammals (Fig. $3 \mathrm{~A}$, center). Some conidia can be ingested by other invertebrates, such as beetles, and the beetles in turn can then be ingested by vertebrate animals such as amphibians or reptiles (Ingold 1934; Gugnani 1999). Once in the intestinal tract of these animals, the primary conidia divide by fission into several cells (sometimes $>50$ ) that are termed meristospores (Fig. 3Af) and can be released in the feces of their vertebrate hosts. Meristospores can survive extreme environmental conditions for several months. Meristospores are then released within the excrement of their vertebrate hosts, and they produce coenocytic mycelia and simple sporangiphores, in which new ballistic conidia will form (Fig. 3Ad). Elongated secondary ballistoconidium can become large cells that continue to replicate by binary fission when sub- cultured in special media, forming globose, dividing, septate cells similar to those observed in the unicellular algae (see Fig. 3Af, within the circled part at the top). These structures are known as "palmella" because of their morphological resemblance to algal cells (Levisohn 1927).

In laboratory culture (Fig. 3A) and in nature, the development of a colony from existing conidia and/or meristospores could lead to the commencement of the sexual stage. Zygospore production is initiated by the formation of septa in adjacent hypha (Fig. 3Ag), both of which develop small protuberances at the site of zygospore formation (Fig. 3Ag-j and Fig. 4B,C). Parallel beaks are formed, in which a nucleus migrates and divides on each side (Eidam 1886). One of the two nuclei at the tip of the beak eventually disintegrates, and the other migrates back into the mother hyphal cell. Meanwhile, the hypha closes and the formed beaks enlarge in size; a pore is then formed that allows the second nucleus to enter the enlarged formation (Fig. 4E). Fusion of the nuclear structures occurs, forming a zygospore with prominent cell walls (Fig. 4C). Mature zygospores (25$50 \mu \mathrm{m})$ may have undulate and/or smooth cell walls (Kian Joe et al. 1956; Gugnani 1999); both types of cell walls have been recorded in the same strain (McGinnis 1980). Thus, this taxonomic characteristic could lead to misidentification. Within the zygospore, meiosis occurs to form four haploid nuclei, of which only one survives. At germination, the zygospore could develop coenocytic hyphae or sporangiphores from which ballistoconidia could be formed, and the life cycle is repeated. Figure 3A depicts the life cycle of Basidiobolus spp.

\section{Conidiobolus spp.}

Species of the genus Conidiobolus have been isolated from dead insects, decaying leaves, keratin, living ferns, rotten vegetables, and soil (KwonChung 2012; Nie et al. 2012). The genus name was introduced by Brefeld in 1884 (Brefeld 1884). Two species, Conidiobolus utriculosis and Conidiobolus minor, were proposed in this study, with $C$. utriculosis as the type species for the 
HFPs of Mucorales and Entomophthorales
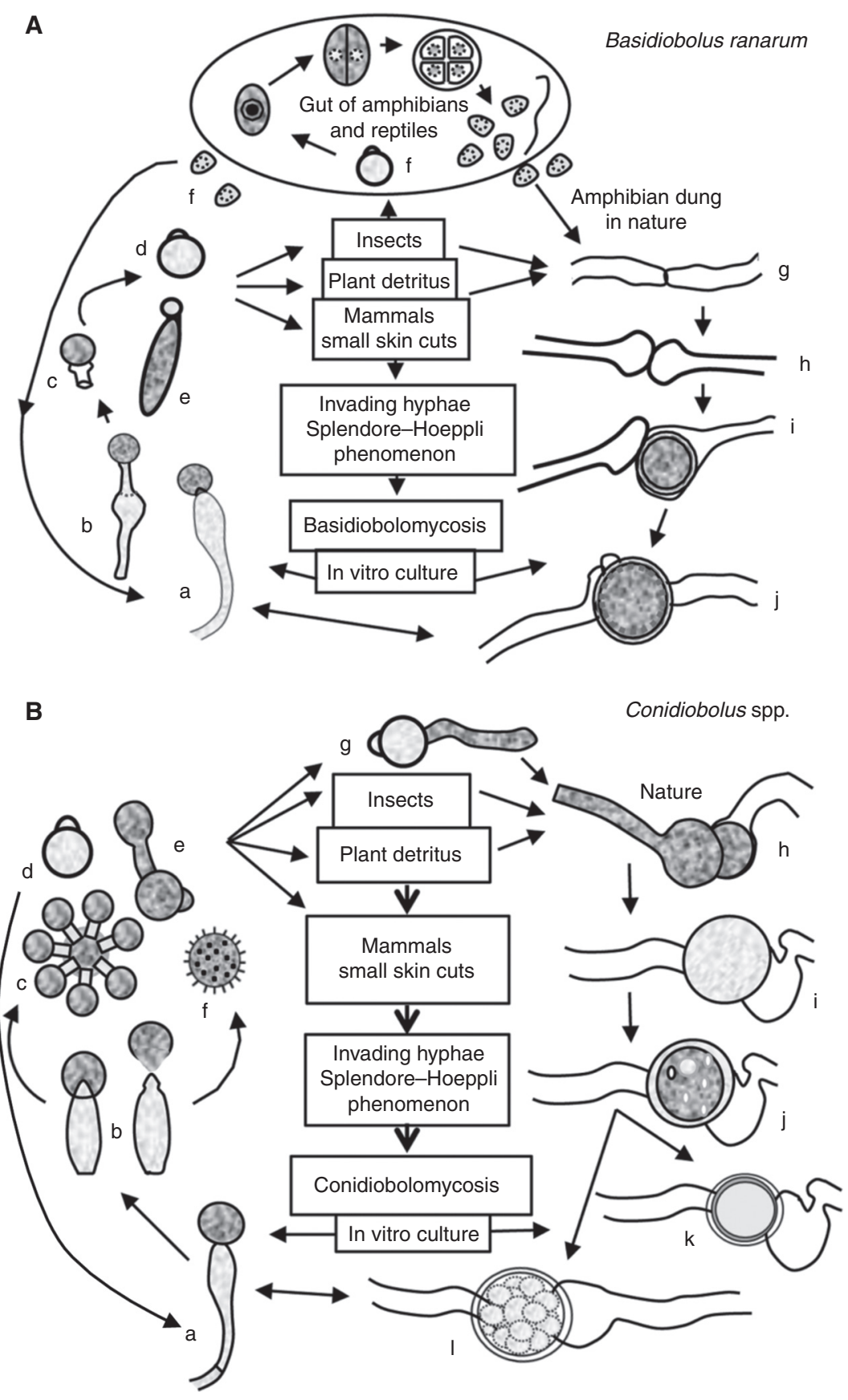

Figure 3. The life cycles of the representative species that cause entomophthoramycosis. $(A)$ The life cycle of Basidiobolus ranarum. The life cycle starts after a single sporangiophore $(a$ and $b)$ forcibly ejects a conidium $(c$ and $d$ ) or after the formation of an elongated sticky "capilliconidium" with a terminal sticky beak (e). Insects or other animals, including mammals, could come into contact with these sticky conidia. Some reptiles and amphibians feed from insects carrying these spores, and a new cycle begins inside their gut $(f)$. Levisohn (1927) observed that a single conidium divided and could produce $>50$ small spores (meristospores), which could survive in dry environments. (Legend continues on following page.) 
L. Mendoza et al.

genus. Unlike the genus Basidiobolus, numerous species (around 33 species [Nie et al. 2012]) have been described; some have been recovered from dead insects and mites and others are parasites of mammals, including C. coronatus (Walker et al. 1992; Fischer et al. 2008; Yang et al. 2010), C. incongruus (Walsh et al. 1994; Temple et al. 2001), and C. lampragues (Vilela et al. 2010; Kimura et al. 2011). Because of their distinctive phenotypic features, most agree on the proper identification among the mammalian-pathogenic species that cause conidiobolomycosis. Vilela et al. described major morphological characteristics displayed by mammalian-pathogenic Conidiobolus spp. in culture (Vilela et al. 2010) that could be used as a guide to properly characterize the isolates.

According to this proposal, the mammalian-pathogenic species could be separated as follows: (1) C. coronatus develops villose conidia (Fig. 3Bf) especially on water agar cultures from solitary sporangiophores (Figs. 3Ba,b,g and 4F, lower part and in the inset). The other two species, C. incongruus and C. lampragues, do not produce villose conidium. This unique conidium is characterized by its spherical shape with numerous short filament-like projections that may or may not cover the entire surface (Fig. $4 \mathrm{~F}$, lower part and in the inset). Conidia of C. coronatus can also produce secondary conidia by replication that cover the surface of the primary conidia, known as multiplicative conidia (Figs. 3Bc and 4G). The secondary conidia are smaller than primary conidia. In addition, the development of zygospores is absent in C. coronatus. (2) C. incongruus can be readily identified in culture by the development of spherical yellowish zygospores, 15-40 $\mu \mathrm{m}$ in diameter. Each contains numerous globules on maturation (Figs. 3Bj and 5D). The large size and the multiple globules within the zygospore of $C$. incongruus are the features that can be used to differentiate the species from C. lampragues, which produces smaller zygospores $(12-18 \mu \mathrm{m}$ in size) that contain homogeneous single globules (Fig. 5E). C. incongruus can also develop single or multiple secondary multiplicative conidia similar to those of $C$. coronatus (Fig. 5B,C). C. lampragues has been recovered from humans, horses, and sheep (Humber et al. 1989; de Paula et al. 2010; Vilela et al. 2010; Kimura et al. 2011). Single and secondary conidia similar to those of $C$. coronatus and $C$. incongruus have been also found in C. lampragues (Fig. 5F). However, multiplicative conidia surrounding a primary conidium, similar to those shown in Figures $3 \mathrm{Bc}$ and $4 \mathrm{G}$, have not been encountered in C. lampragues. Conidiobolus spp. that are pathogenic to mammals develop conidia at the apices of primary sporangiophores that are then forcibly discharged. These conidia (Fig. 3Bd) are globose to pyriform and have species-specific morphological features. For instance, C. incongruus develops conidia with sharp pyriform papilla (Fig. 5A,C), whereas in C. coronatus (Fig. $4 \mathrm{~F}$ ) and Clampragues (Fig. 5F,G), this protuberance is smooth.

Although the life cycle of Conidiobolus spp. (Fig. 3B) is similar to that of Basidiobolus (Fig. 3A), key differences exist. Conidiobolus spp. develop a different type of asexual conidia (King 1983). For example, C. coronatus produces at

Figure 3. (Continued.) After being released into the environment, they develop short mycelia and produce single sporangiophores; alternatively, the nuclei in the same hyphae could exchange genetic material and develope zygospores $(g-j)$. They can also develop into structures called palmella, which resemble green algae. Mammals inhabiting areas of endemicity can contact B. ranarum propagules through trauma and develop zygomycosis (center). (B) The life cycle of the pathogenic Conidiobolus species. A single conidiophore develops terminal conidia ( $a$ and $b$ ), which are forcibly ejected $(d)$ using a mechanism different from that in the genus Basidiobolus (see taxonomy) and geminate $(g)$. Most species that are pathogenic to mammals can develop replicative conidia ( $c$ and $e$ ), but the "villose" conidia $(f)$ can only be found in $C$. coronatus. These conidia could develop more sporangiophores or repeat the cycle, or the nuclei of the same coenocytic hyphae could form a septum and develop into a zygospore $(h-l)$. Drawings of $k$ and $l$ are examples of $C$. lampragues and C. incongruus zygospores, respectively. 


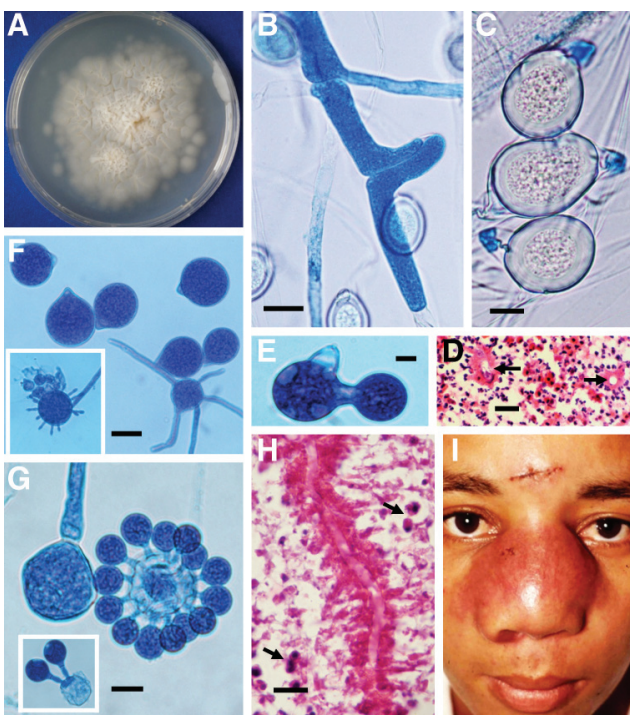

Figure 4. Mycological and clinical aspects of Basidiobolus ranarum. (A) A culture of $B$. ranarum on $2 \%$ Sabouraud dextrose agar after $4 \mathrm{~d}$ incubation at $37^{\circ} \mathrm{C}$. Note the small colonies formed by forcibly ejected conidia growing around the edges of the culture. $(B)$ Coenocytic hypha of $B$. ranarum forming the first septum and the elongation across the plane in which the future zygospore will develop. $(C)$ Three mature zygospores with thick walls and their prominent beaks. Note the Splendore-Hoeppli phenomenon around the empty, round hyphal structures in a histological section ( $D$, arrows). (E) Single replicative conidium formation in Conidiobolus coronatus. $(F)$ C. coronatus conidia with a typical basal papilla, which marks the residual section formed after ejection. The inset of panel $F$ shows a villose conidium. $(G)$ C. coronatus multiplicative secondary conidia around a single conidium. The left portion of panel $G$ shows a sporangiophore before conidium discharge. The inset depicts two multiplicative conidia. $(H)$ The eosinophilic inflammatory response and longitudinal sectioned hyphae of $C$. coronatus surrounded by an eosinophilic reaction. The presence of numerous eosinophils (arrows) is noted. (I) A young boy with bilateral rhinofacial infection caused by $C$. coronatus. Note the scar of the biopsy performed for diagnostic purposes. (Courtesy of Rafael Isa-Isa and Roberto Arenas.) Scale bars, $25 \mu \mathrm{m}(B) ; 10 \mu \mathrm{m}(C) ; 18 \mu \mathrm{m}$ $(D) ; 15 \mu \mathrm{m}(E, G) ; 23 \mu \mathrm{m}(F) ; 19 \mu \mathrm{m}(H)$.

least four types of asexual conidia (King 1977). Some members of the genus (except C. coronatus) readily develop zygospores (sexual spores). The life cycle starts with the formation of uni-
HFPs of Mucorales and Entomophthorales

or multinucleate conidia that are produced at the apices of simple solitary sporangiophores, which emerge from vegetative coenocytic hyphae (Fig. 3Ba). Conidiobolus spp. eject their conidia by the cell wall invagination pressure exerted at the base of the sporangiophore, which causes a sudden eversion of this portion of the cell wall (Fig. 3Bb). The conidia on the sporangiophore of Conidiobolus spp. have a strong phototropism that stimulates their release (King 1983). The eversion of the conidial cell wall in contact with the sporangiophore results in the species-specific morphology of conidial papilla (Fig. 3Bd). The formation of zygospores occurs in the same hyphae, as illustrated in Fig. 3Bh-l; "k" shows a C. lampragues zygospore, and "l" depicts the zygospore of $C$. incongruus.
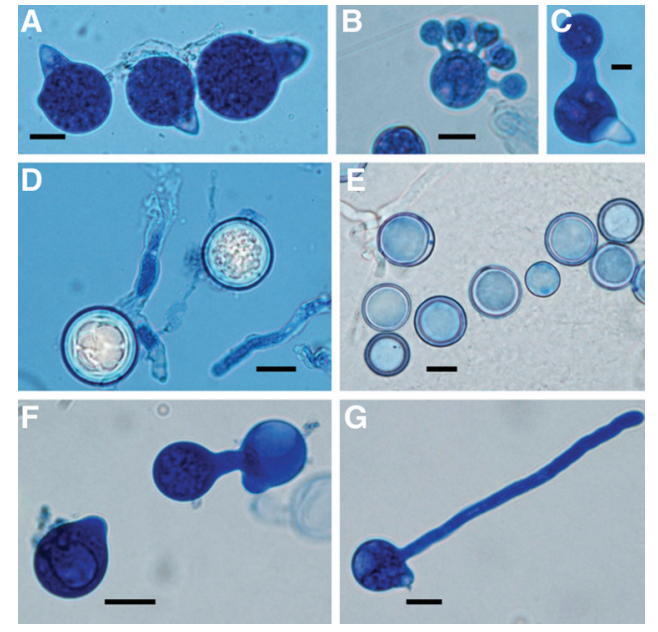

Figure 5. Mycological characteristics of Conidiobolus incongruus. (A) Three C. incongruus conidia with characteristic sharp papillae. (B) An example of multiple replicative conidia of $C$. incongruus. $(C)$ A conidium with a sharp papilla and a single secondary replicative conidium. (D) Characteristic thick-walled zygospores of $C$. incongruus containing multiple hyaline globular structures in their cytoplasm. (E) Multiple zygospores of $C$. lampragues with homogeneous cytoplasm. ( $F$ and $G$ ) C. lampragues conidia with smooth papillae and the formation of a hypha from a primary conidium, respectively. Scale bars, $14 \mu \mathrm{m}$ $(A) ; 20 \mu \mathrm{m}(B) ; 15 \mu \mathrm{m}(C, F) ; 28 \mu \mathrm{m}(D) ; 17 \mu \mathrm{m}$ $(E) ; 17 \mu \mathrm{m}(G)$. 
L. Mendoza et al.

Pathogenesis and Clinical and Pathological Features

\section{Pathogenesis}

The infection of mammalian species with the members of Entomophthoromycota begins with the attachment of an ejected sticky spore into or near an open wound. The use of plants for play or to cover body parts has been implicated as a possible mode of infection acquisition (Gugnani 1999). The route of intestinal infection caused by Basidiobolus spp. is more likely the ingestion of food containing pathogenic propagules. As the pathogen is known to invade the intestines and adjacent tissues (de Aguiar et al. 1980; Khan et al. 2001), the presence of small cuts in the mucosal surface of the intestine is a more likely scenario for pathogen access to the intestinal mucosa. Once the conidia attach to open surfaces and are stimulated by host temperature, they germinate and penetrate open skin or small cuts on the mucosal surface (Fig. $3 \mathrm{~A}, \mathrm{~B}$, life cycle). Susceptible hosts stimulated by release of antigens from germinating conidia trigger a local inflammatory response composed of neutrophils, active macrophages, and eosinophils (Th2) but the pathogens seem to survive this initial attack and further spread to adjacent tissues. Detection of interleukin 10, interleukin 4, and tumor necrosis factor $\alpha$, all cytokines related to the Th2 immunogenic response to $B$. ranarum infection, tend to confirm the presence of a typical Th2 response in the infected tissues triggered by members of the Entomophthoromycota (Khan et al. 2001). The production of eosinophilic material around the invading hypha (Splendore-Hoeppli phenomenon) is apparently formed by the degranulation of eosinophils and mast cells over both Basidiobolus and Conidiobolus invading hyphae, in the same manner as previously reported in infections caused by Lagenidium spp. and P. insidiosum (Gugnani 1999; Mendoza and Newton 2005; Mendoza and Vilela 2013).

\section{Clinical and Pathological Features}

Basidiobolomycosis. Basidiobolomycosis is caused by $B$. ranarum (see above nomencla- ture), a pathogen that mainly affects the subcutaneous tissues and the intestinal tract of susceptible hosts and less frequently internal organs (Dworzack et al. 1978; Gugnani 1999; Kwon-Chung 2012). The first published case of Basidiobolus infection occurred in an Indonesian horse, causing an ulcerative subcutaneous infection in one of the horse's limbs (Van Overeem 1925). Kian Joe et al. diagnosed the first cases of basidiobolomycosis in humans 31 years later, again in Indonesia (Kian Joe et al. 1956). The cases were described as swelling masses in the subcutaneous pectoral region on 4- and 8-yr-old boys (Kian Joe et al. 1956). The infection started $\sim 6$ mo earlier as small nodules (papules) that slowly progressed to cover most of the thoracic area. Remarkably, the patients did not have fever or pain, and their general conditions were considered good. These cases can be used to illustrate the typical clinical features encountered in most subcutaneous basidiobolomycosis cases, with the enlargement of regional lymph nodes sometimes mimicking Burkitt's lymphoma (Bittencourt et al. 1982). The anatomical distribution of the lesions includes upper and lower limbs, thorax, and abdomen, and more rarely the neck, trunk, and face (Koshi et al. 1972; Gugnani 1999). The skin on the subcutaneous tumor-like masses does not indent when pressure is applied. The disease occurs predominantly in male children (1-20 year old) and less frequently in adults. Historically, in some African countries, the male-tofemale ratio of basidiobolomycosis patients was $3: 1$, whereas in other countries it was as high as 3:2 (Blanché et al. 1961). Basidiobolomycosis has been also recorded in horses (Miller and Campbell 1982) and dogs (Miller 1985). Although the subcutaneous form of the disease could slowly spread to adjacent tissues, it is considered a benign disease with a high morbidity but low mortality rate (Edington 1964; Gugnani 1999). However, in unusual cases with the involvement of internal anatomical sites, the clinical signs are difficult to interpret; the intestinal form of basidiobolomycosis is one such example.

Although subcutaneous basidiobolomycosis is relatively easy to recognize, the intestinal 
form is difficult to diagnose because the symptoms are nonspecific. Moreover, there are no distinct risk factors and it does not occur in a specific age group (Khan et al. 2001). Some intestinal basidiobolomycosis cases have been diagnosed in apparently healthy hosts, whereas others have been recorded in patients with predisposing factors or problems with the immune system (Khan et al. 2001; Kimura et al. 2011). The first case of intestinal basidiobolomycosis was reported by Onuigbo and Gugnani (1976). After this report, several other cases have been diagnosed without culture, using the distinctive Splendore-Hoeppli phenomenon as a clue for diagnosis. The first patient with intestinal basidiobolomycosis confirmed by culture was published 6 years later (Schmidt et al. 1986) after the report of de Aguiar et al. (1980). Some of the clinical symptoms related to $B$. ranarum intestinal infection previously reported by others include (1) epigastric abdominal pain; (2) low fever; (3) bloody mucous diarrhea; and (4) the presence of tumor-like masses in the stomach and intestinal tissues and sporadic involvement of the regional lymph nodes, liver, and pancreas (Onuigbo and Gugnani 1976; de Aguiar et al. 1980; Pasha et al. 1997). Intestinal basidiobolomycosis could mimic inflammatory bowel disease, colon carcinoma, Crohn's disease, and intestinal mucormycosis (Onuigbo and Gugnani 1976; Bittencourt et al. 1982; Pasha et al. 1997; Gugnani 1999; Hassan et al. 2013). In addition, unusual cases of $B$. ranarum affecting lungs (Bittencourt et al. 1980), lymph nodes (Kamalam and Thambiah 1979), maxillary sinus and palate (Dworzack et al. 1978), and muscles (Kamalam and Thambiah 1982) have been also recorded. Secondary bacterial infection of the ulcerated tissue is common.

Biopsied tissue of the tumor-like masses must be collected for histopathology and the clinical laboratory. Histological sections of the affected tissue stained with hematoxylin and eosin show the typical inflammatory reaction, including numerous eosinophils, mast cells, neutrophils, and lymphocytes. Some eosinophils seem to fuse their granules to the invading hyphae, forming an eosinophilic hyaline mate- rial known as the Splendore-Hoeppli phenomenon (see above). Fibrotic tissue containing numerous eosinophilic micro-abscesses and giant cells can be found. A characteristic feature of the infection is the presence of longitudinal and transversal 4 - to $12-\mu \mathrm{m} B$. ranarum hyphae surrounded by an eosinophilic hyaline material at the center of the eosinophilic micro-abscesses (Owen et al. 1985; Gugnani 1999). Infiltration of blood vessels by this pathogen is uncommon; in contrast, members of the Mucorales are consistently found in the lumen of blood vessels and cause vascular thrombosis (Ribes et al. 2000).

\section{Conidiobolomycosis}

Although $>33$ Conidiobolus spp. have been described, only three have been reported as agents of conidiobolomycosis in humans and lower animals: C. coronatus, C. incongruus, and $C$. lampragues. Infections caused by Conidiobolus spp. are largely restricted to the subcutaneous tissues of the face, typically around the nose, and rarely on other anatomic areas (Fig. 4I) (Onuigbo and Gugnani 1976). However, dissemination to internal organs has been reported (Onuigbo and Gugnani 1976; Walsh et al. 1994). The clinical location of the lesions caused by $B$. ranarum and Conidiobolus spp. tends to differ. The main clinical and pathological characteristics of each species are highlighted below.

\section{C. coronatus}

The classical clinical features of $C$. coronatus infection were first described in a man with rhinofacial swelling in south Cameroon (Blanché et al. 1961). It is now apparent that $C$. coronatus infection in mammals is often observed in the nasal area of susceptible hosts (Isa-Isa et al. 2012); this is a characteristic also present in infections caused by the other two Conidiobolus spp. that infect humans, horses, and sheep (Hernandez et al. 2007; Fischer et al. 2008; Kimura et al. 2011). Bridges et al. (1962) reported cases of horses developing tumor-like masses around the nares causing obstruction of the na- 
L. Mendoza et al.

sal passages. Since the initial reported cases, numerous additional cases have been reported in horses (Mendoza and Alfaro 1985). Interestingly, small masses, termed "kunkers" by some, are recovered only from the tissues of infected horses (Mendoza and Alfaro 1985); these soft masses have not been described in humans. Most diagnosed human cases of $C$. coronatus infection are in African adults; however, cases have also been reported in Asia and Latin America (Bittencourt et al. 1979; Yang et al. 2010; IsaIsa et al. 2012). Cases of conidiobolomycosis in the United States and Australia have been diagnosed mainly in horses and dogs (Miller and Campbell 1982).

In humans, C. coronatus infection starts with a small subcutaneous nodule, caused by invading hyphae, in the rhinofacial area that slowly invades the adjacent tissues and becomes bilateral, affecting both sides of the nose (Fig. 4I). The swelling can spread to the cheek, eyes, upper lip, pharynx, and sinus. Thus, nasal obstruction, rhinorrhea, epistaxis, and weight loss are common features of the disease (McGinnis 1980; Yang et al. 2010; Isa-Isa et al. 2012). In severe chronic cases, bacterial sinusitis is an unwelcome complication of the infection. Infected hosts may be exposed to environmental C. coronatus propagules through small cuts in the skin (see the section on Ecology and Epidemiology above). Cases of C. coronatus systemic involvement have also been recorded (Walker et al. 1992).

\section{C. lampragues}

Few reports of conidiobolomycosis caused by C. lampragues have been so far recorded, with the majority occurring in animals (Humber et al. 1989; Vilela et al. 2010) and one disseminated case in a human (Kimura et al. 2011). The first diagnosed case of $C$. lampragues infection was in an Arabian mare from Louisiana (Humber et al. 1989). The typical clinical features of C. coronatus (affliction of nasal passages) infection reported earlier by Bridges et al. (1962) in horses in Texas were also observed in the Louisiana case. The case reported by Humber et al. described episodes of epistaxis and severe weight loss (Humber et al. 1989). At necropsy, an $8-\mathrm{cm}$ mass was found in the rear palate and near the pharyngeal area. Numerous small masses (kunkers) were also found in both guttural pouches (see section on Laboratory Diagnosis below). The clinical features of the first cases of conidiobolomycosis caused by C. lampragues in sheep were published by Riet-Correa et al. (2008) in Paraiba, Brazil. The proper identification of the etiology using molecular and taxonomic tools was described in a later report (Vilela et al. 2010). The description of C. lampragues in sheep from Mato Grosso, Brazil, was published shortly after (de Paula et al. 2010). The affected anatomical areas were the rhinofacial and rhinopharyngeal areas. The clinical signs of rhinofacial conidiobolomycosis were prominent swelling of the nostrils and face, dyspnea, and bilateral serosanguineous discharge (Riet-Correa et al. 2008). Sheep with the rhinopharyngeal form of the disease developed mechanical obstruction of the nasal cavities, swelling of the nose, and serosanguinous discharge. Some of the affected sheep showed exophthalmia, keratitis, and corneal ulceration (Riet-Correa et al. 2008). Dense yellow exudates were observed on the turbinate bones, paranasal sinus, soft palate, orbital cavity, and pharynges. The regional lymph nodes and muscular tissues were also involved. P. insidiosum was also found to affect the rhinopharyngeal tissue of Brazilian sheep, indicating that an accurate differential diagnosis is essential for appropriate management of the infection.

The only human case of $C$. lampragues infection was diagnosed in a 61-year-old Japanese worker with relapsed lymphoma and severe neutropenia as a result of chemotherapy (Kimura et al. 2011). The patient developed bilateral lung infiltration and other complications, including pancreatitis, and finally died of respiratory failure. At necropsy ribbon-like hyphae were detected in the bladder, heart, kidneys, lungs, spleen, urethra, and thyroid gland. In histopathology two types of hyphae were described: a type resembling the Mucorales and dichotomous septate hyphae resembling Aspergillus spp. C. lampragues was isolated in culture from the infected tissues. Surprisingly, the hyphae in the 
HFPs of Mucorales and Entomophthorales

infected tissues did not show the typical Splendore-Hoeppli phenomenon characteristic of the entomophthoraceous fungi, attributable in part to the immune status of the host. Although C. lampragues infection in animals was found to affect the rhinofacial and rhinopharyngeal areas, the only human case of infection by $C$. lampragues involved internal organs similar to systemic cases reported in C. coronatus (Walker et al. 1992) and C. incongruus infection (Bittencourt et al. 1979; Walsh et al. 1994).

\section{C. incongruus}

C. incongruus has been recovered from facial and systemic infections in humans, sheep, and deer (Carrigan et al. 1992; Ketterer et al. 1992; Madson et al. 2009). The first recorded case of C. incongruus infection in humans was diagnosed by Gilbert et al. in 1970, but the recovered organism was properly identified 6 yr later by King and Jong (1976). C. incongruus infections have been diagnosed in both apparently normal and immunocompromised hosts (Walsh et al. 1994; Wuppenhorst et al. 2010). An important difference between $C$. incongruus and the other pathogenic Conidiobolus species is the clinical presentation of the infection. The majority of diagnosed cases, some fatal, show systemic involvement of several internal organs (Busapakum et al. 1983; Ketterer et al. 1992; Hernandez et al. 2007). Since the first report, at least three more patients have been diagnosed with orbitofacial and orofacial conidiobolomycosis (Eckert et al. 1972; Busapakum et al. 1983; Al-Hajjar et al. 1996), and nine systemic cases involving one or more organs have been reported (Eckert et al. 1972; Busapakum et al. 1983; Walsh et al. 1994; Hernandez et al. 2007; Wuppenhorst et al. 2010). C. incongruus infection has been also diagnosed in sheep, causing rhinofacial infection (Ketterer et al. 1992), and in a deer, causing systemic dissemination (Madson et al. 2009). Thus, C. incongruus more commonly causes disseminated infections and seldom causes localized infection, a clinical feature in contrast to that of C. coronatus (Walker et al. 1992; Walsh et al. 1994; Wuppenhorst et al. 2010).

\section{Laboratory Diagnosis}

\section{Serology, Wet Mount, and Culture}

Standardized serological tests for the diagnosis of basidiobolomycosis and conidiobolomycosis are not available. However, several studies using immunodiffusion showed that, whereas some antigens extracted from $B$. ranarum cross-reacted with the antigens of Conidiobolus spp. and P. insidiosum, others were specific (Yangco et al. 1986; Kaufman et al. 1990). Moreover, antibodies against Basidiobolus and Conidiobolus from infected patients were detected using western blot and enzyme-linked immunosorbent assay analyses, suggesting that these serological assays could be used as a diagnostic tool (Mendoza et al. 1992; Khan et al. 2001).

A fresh section of biopsied tissue must be submitted to the clinical laboratory for culture and microscopic evaluation. The biopsy specimen must be cut into $2 \mathrm{~mm} \times 2 \mathrm{~mm}$ blocks and then placed on a slide glass with one drop of $10 \% \mathrm{KOH}$. The microscopic visualization of ribbon-type sparsely septate hypha covered by a hyaline material is indicative of a presumptive infection by members of the Entomophthoromycota. Likewise, a 2-mm block of biopsied tissue must be implanted onto $2 \%$ Sabouraud dextrose agar plates and incubated at $37^{\circ} \mathrm{C}$ and $25^{\circ} \mathrm{C}$. After $24-48 \mathrm{~h}$ of incubation at $37^{\circ} \mathrm{C}$, small glabrous colonies are usually detected around the implanted tissues (Fig. 3A). As the colony ages, numerous ballistoconidia, ejected from sporangiophores, can be observed on the surface of the agar and attached to the inner side of the culture plate lid. The presence of zygospores with undulate and smooth cell walls can be readily found. The development of zygospores on $2 \%$ Sabouraud dextrose agar plates is necessary for proper identification of $B$. ranarum in culture (Fig. 4A,C).

Conidiobolus spp. can be identified in culture following the diagram proposed by Vilela et al. (2010). According to the chart, the presence of villose conidia is the main criterium to separate C. coronatus from the other two pathogenic species (Fig. 4F, inset). C. incongruus can be readily identified by the development of typical zygospores that can be easily differenti- 
L. Mendoza et al.

ated from those produced by C. lampragues. C. incongruus develops larger zygospores (15$40 \mu \mathrm{m}$ ) with numerous globules (Fig. 5D), whereas C. lamparagues zygospores are smaller $(12-18 \mu \mathrm{m})$ and display a single globule within the zygospore (Fig. 5E).

\section{Histopathology}

The histopathological characteristics of basidiobolomycosis and conidiobolomyosis in infected tissues are similar (Fig. 4D,H). The main characteristic is the formation of an eosinophilic halo around the hyphae after hematoxylin and eosin staining (Splendore-Hoeppli phenomenon) mostly found at the center of proliferative eosinophilic micro-abscesses (Fig. $4 \mathrm{D}, \mathrm{H})$. Hyaline coenocytic or sparsely septated hyphae $5-12 \mu \mathrm{m}$ in diameter are usually present as long ribbon-type hyphae (Fig. $4 \mathrm{H}$ ) or as small round structures, with the hyphae transversely sectioned (Fig. 4D, arrows). In early infection, the presence of an acute inflammatory response with neutrophils, eosinophils, and lymphocytes can also be found (Fig. $4 \mathrm{H}$, arrows). In chronic lesion fibrosis, eosinophils, histiocytes, and multinucleated giant cells are also encountered. Although the lack of the eosinophilic material around the invading hyphae has been reported in immunocompromised hosts, the Splendore-Hoeppli phenomenon is an important histopathological characteristic of the mammalian-pathogenic Basidiobolus spp. and Conidiobolus spp. (Kimura et al. 2011). This feature has been used to differentiate infections caused by members of the Mucorales and Entomophthoromycota (McGinnis 1980; Kwon-Chung 2012). However, cases such as those reported by Kimura et al. and those caused by Mucorales must be interpreted with caution because the morphological features of their hyphae are identical. Moreover, eosinophilic material around the invading hyphae is also present around the hyphae of the infected tissues in mammalian-pathogenic oomycetes (P. insidiosum and Lagenidium spp.), affecting the differential diagnosis of entomophthoramycosis (Miller and Campbell 1984; Mendoza and Vilela 2013).

\section{Management}

Successful treatment outcome is directly correlated to an early diagnosis. In chronic infections caused by Conidiobolus spp. and Basidiobolus spp., the formation of fibrotic tissues around the eosinophilic micro-abscesses influences the contact of antifungals and KI (potassium iodide) with the invading hyphae (Table 3) (Gugnani 1999). Thus, decreasing levels of the antifungals trimethoprim-sulfamethoxazole and/or KI in the infected areas reduce the action of the chemotherapeutic agent (Fomufod and Antia 1971; Yangco et al. 1984; Nazir et al. 1997). The limiting factors of oral KI include the following: (1) gastric intolerance, (2) thyroid metabolic disturbances, and (3) drug hypersensitivity. However, oral KI $(40 \mathrm{mg} / \mathrm{kg}$ daily) for 4-6 wk has been successful in some cases of facial conidiobolomycosis (Kamalam and Thambiah 1982; Nazir et al. 1997; Krishnan et al. 1998).

Sensitivity studies have shown in vitro multidrug resistance in most Conidiobolus spp. recovered from both humans and animals, including C. lampragues (Kimura et al. 2011; Choon et al. 2012; Tondolo et al. 2013). In contrast, in vitro studies of B. ranarum showed inhibitory and fungicidal susceptibility to miconazole and ketoconazole (400 mg daily) (Villasco et al. 1966; Saka et al. 2010) and some clinical response to AmB, itraconazole $(200 \mathrm{mg}$ per day), and fluconazole (Randhawa et al. 1994). However, treatment with $\mathrm{AmB}$ alone has given unsatisfactory results (Khan et al. 2001). B. ranarum infection has been treated

Table 3. The most common factors interfering with the therapeutic outcome of infections caused by Conidiobolus and Basidiobolus species

1. Extensive, chronic lesions

2. Extensive fibrosis

3. Host immunity

4. Surgical resection or debridement in critical anatomical areas

5. Late diagnosis of the infection

6. Low host tolerance to some drugs (i.e., amphotericin B and KI)

7. Inadequate drug levels at site of infection 
with $\mathrm{KI}$ as a single daily dose of $30 \mathrm{mg} / \mathrm{kg}$ body weight for 5 mo to 1 yr (Gugnani 1999). Regardless, most antifungals and KI have been used to treat basidiobolomycosis with some success (Gugnani 1999). Surgery and debridement of the affected tissues can also be successful, especially when combined with chemotherapy (Prabhu and Patel 2004).

Although spontaneous resolution has been documented for some $B$. ranarum infections (Burkitt et al. 1964; Atonelli et al. 1987), successful management of basidiobolomycosis is usually directly associated with the chronic status of the lesion (Table 3). Several cases, including the intestinal form of the disease, have been successfully treated with KI (Kamalam and Thambiah 1979; Nazir et al. 1997). However, patients unresponsive to KI should continue treatment with ketoconazole (Nazir et al. 1997; Gugnani 1999), trimethoprim-sulfamethoxazole (Fomufod and Antia 1971), or itraconazole (200 mg daily). Although C. coronatus is susceptible to $\mathrm{AmB}$, the prognosis of this infection is always reserved. Most antifungal drugs and KI have resulted in unsatisfactory outcomes in most cases of conidiobolomycosis over the past 40 years (Yangco et al. 1984). Surgery and debridement have been also used in cases of $\mathrm{Co}$ nidiobolus spp. infection, resulting in some success. Complete cure of the infection had been achieved in some patients, mostly those with early diagnosis (Kelly et al. 1980; Nazir et al. 1997; Krishnan et al. 1998; Gugnani 1999).

\section{ACKNOWLEDGMENTS}

The authors thank Kerstin Kaerger (University of Jena, Jena, Germany) for assistance with Figure 2 .

\section{REFERENCES}

Abe F, Inaba H, Katoh T, Hotchi M. 1990. Effects of iron and desferrioxamine on Rhizopus infection. Mycopathologia 110: $87-91$.

Abe A, Oda Y, Asano K, Sone T. 2007. Rhizopus delemar is the proper name for Rhizopus oryzae fumaric-malic acid producers. Mycologia 99: 714-722.
Abzug MJ, Walsh TJ. 2004. Interferon- $\gamma$ and colony-stimulating factors as adjuvant therapy for refractory fungal infections in children. Pediatr Infect Dis J 23: 769-773.

Alastruey-Izquierdo A, Hoffmann K, de Hoog GS, Rodriguez-Tudela JL, Voigt K, Bibashi E, Walther G. 2010. Species recognition and clinical relevance of the zygomycetous genus Lichtheimia (syn. Absidia Pro Parte, Mycocladus). J Clin Microbiol 48: 2154-2170.

Al-Hajjar S, Perfect J, Hashem F, Tufenkeji H, Kayes S. 1996. Orbitofacial conidiobolomycosis in a child. Pediatr Infect Dis J 15: 1130-1132.

Antonelli M, Vignetti P, Dahir M, Mohammed M, Favah AA. 1987. Entomophthoromycosis due to Basidiobolus in Somalia. Trans R Soc Trop Med Hyg 81: 86-187.

Artis WM, Fountain JA, Delcher HK, Jones HE. 1982. A mechanism of susceptibility to mucormycosis in diabetic ketoacidosis: Transferrin and iron availability. Diabetes 31: 1109-1114.

Ben-Ami R, Luna M, Lewis RE, Walsh TJ, Kontoyiannis DP. 2009. A clinicopathological study of pulmonary mucormycosis in cancer patients: Extensive angioinvasion but limited inflammatory response. J Infect 59: 134-138.

Benjamin RK. 1962. A new Basidiobolus that form microspores. Aliso 5: 223-233.

Benjamin RK. 1979. The whole fungus: II. In Proceedings of the 2nd International Mycological Conference (ed. Kendrick B), pp. 573-616. National Museum of Natural Sciences, National Museums of Canada, and the Kananaskis Foundation, Environmental Sciences Centre of the University of Calgary, Kananaskis, Alberta, Canada.

Benny GL, Humber RA, Morton JB. 2001. Zygomycota: Zygomycetes. In The Mycota, Vol. VIIA: Systematics and evolution (ed. McLaughlin DJ, et al.), pp. 113-146. Springer, Berlin.

Berbee M, Taylor J. 2001. Fungal molecular evolution: Gene trees and geological time. In The Mycota, Vol. VIIA Systemics and evolution (ed. McLaughlin DJ, et al.), pp. 229-245. Springer, Berlin.

Bittencourt AL, Ayala MAR, Ramos EAG. 1979. A new form of abdominal zygomycosis different from mucormycosis: Report of two cases and review of the literature. Am J Trop Med Hyg 28: 564-569.

Bittencourt AL, Araujo MG, Fontoura MS. 1980. Occurrence of subcutaneous zygomycosis (entomophthoromycosis basidiobolae) caused by Basidiobolus haptosporus with pulmonary involvement. Mycopathologia 71: $155-158$.

Bittencourt AL, Serra G, Sadigursky M, Araujo MG, Campos MC, Sampaio LC. 1982. Subcutaneous zygomycosis caused by Basidiobolus haptosporus: Presentation of a case mimicking Burkitt's lymphoma. Am J Trop Med Hyg 31: $370-373$.

Blair JE. 2009. Fungi. In The timetree of life (ed. Hedges SB, Kumar S), pp. 215-219. Oxford University Press, New York.

Blanché RP, Destombes P, Nazimoff O. 1961. New subcutaneous mycoses in Southern Cameroon [Nouvelle mycoses sous-cutaneous au Sud-Cameroun]. Bull Soc Pathol Exot 54: 56-63.

Blin N, Morineau N, Gaillard F, Morin O, Milpied Nl, Harousseau J-L, Moreau P. 2004. Disseminated mucormy- 


\section{Mendoza et al.}

cosis associated with invasive pulmonary aspergillosis in a patient treated for post-transplant high-grade nonHodgkin's lymphoma. Leuk Lymphoma 45: 2161-2163.

Boelaert JR, van Roost GF, Vergauwe PL, Verbanck JJ, de Vroey C, Segaert MF. 1988. The role of desferrioxamine in dialysis-associated mucormycosis: Report of three cases and review of the literature. Clin Nephrol 29: 261-266.

Boelaert JR, Fenves AZ, Coburn JW. 1989. Mucormycosis among patients on dialysis. N Engl J Med 321: 190-191.

Boelaert JR, Fenves AZ, Coburn JW. 1991. Deferoxamine therapy and mucormycosis in dialysis patients: Report of an international registry. Am J Kidney Dis 18: 660-667.

Boelaert JR, de Locht M, Van Cutsem J, Kerrels V, Cantinieaux B, Verdonck A, Van Landuyt HW, Schneider YJ. 1993. Mucormycosis during deferoxamine therapy is a siderophore-mediated infection. In vitro and in vivo animal studies. J Clin Invest 91: 1979-1986.

Boelaert JR, Van Cutsem J, de Locht M, Schneider YJ, Crichton RR. 1994. Deferoxamine augments growth and pathogenicity of Rhizopus, while hydroxypyridinone chelators have no effect. Kidney Int 45: 667-671.

Bouchara JP, Oumeziane NA, Lissitzky JC, Larcher G, Tronchin G, Chabasse D. 1996. Attachment of spores of the human pathogenic fungus Rhizopus oryzae to extracellular matrix components. Eur J Cell Biol 70: 76-83.

Bras G, Gordon CC, Emmons CW, Prendegast KM, Sugar M. 1965. A case of phycomycosis observed in Jamaica; infection with Entomophthora coronata. Am J Trop Med Hyg 14: 141-145.

Brefeld O. 1884. Conidiobolus utricolosis und minor. Untersuchungen aus dem Gesamtgebiete der. Mykologie 4: $75-$ 78.

Bridges CH, Romane WM, Emmons CW. 1962. Phycomycosis of horses caused by Entomophthora coronata. J Am Vet Med Assoc 140: 673-677.

Burkitt DP, Wilson AMM, Jellife DB. 1964. Subcutaneous phycomycosis: A review of 31 cases seen in Uganda. $\mathrm{Br}$ Med J 1: 1669-1672.

Busapakum R, Youngchaiyud U, Sriumpai S, Segretain G, Fromentin H. 1983. Disseminated infection with $\mathrm{Co}$ nidiobolus incongruus. Sabouraudia 21: 323-330.

Carrigan MJ, Small AC, Perry GH. 1992. Ovine nasal zygomycosis caused by Conidiobolus incongruus. Aust Vet $J$ 69: $237-240$.

Chakrabarti A, Chatterjee SS, Das A, Panda N, Shivaprakash MR, Kaur A, Varma SC, Singhi S, Bhansali A, Sakhuja V. 2009. Invasive zygomycosis in India: Experience in a tertiary care hospital. Postgrad Med J 85: 573-581.

Chamilos G, Lewis RE, Kontoyiannis DP. 2008a. Delaying amphotericin B-based frontline therapy significantly increases mortality among patients with hematologic malignancy who have zygomycosis. Clin Infect Dis 47: 503509.

Chamilos G, Lewis RE, Lamaris G, Walsh TJ, Kontoyiannis DP. 2008b. Zygomycetes hyphae trigger an early, robust proinflammatory response in human polymorphonuclear neutrophils through Toll-like receptor 2 induction but display relative resistance to oxidative damage. Antimicrob Agents Chemother 52: 722-724.
Chamilos G, Ganguly D, Lande R, Gregorio J, Meller S, Goldman WE, Gilliet M, Kontoyiannis DP. 2010. Generation of IL-23 producing dendritic cells (DCs) by airborne fungi regulates fungal pathogenicity via the induction of $\mathrm{T}_{\mathrm{H}^{-}} 17$ responses. PLOS ONE 5: e12955.

Chayakulkeeree M, Ghannoum M, Perfect J. 2006. Zygomycosis: The re-emerging fungal infection. Eur J Clin Microbiol Infect Dis 25: 215-229.

Chen Y-L, Kozubowski L, Cardenas M, Heitman J. 2010. On the roles of calcineurin in fungal growth and pathogenesis. Curr Fungal Infect Rep 4: 244-255.

Chinn RY, Diamond RD. 1982. Generation of chemotactic factors by Rhizopus oryzae in the presence and absence of serum: Relationship to hyphal damage mediated by human neutrophils and effects of hyperglycemia and ketoacidosis. Infect Immun 38: 1123-1129.

Choon S-E, Kang J, Neafie RC, Ragsdale B, Klassen-Fischer M, Carlson JA. 2012. Conidiobolomycosis in a young Malaysian woman showing chronic localized fibrosing leukocytoclastic vasculitis: A case report and meta-analysis focusing on clinicopathologic and therapeutic correlations with outcome. Am J Dermatopathol 34: 511-522.

Couch L, Theilen F, Mader JT. 1988. Rhinocerebral mucormycosis with cerebral extension successfully treated with adjunctive hyperbaric oxygen therapy. Arch Otolaryngol Head Neck Surg 114: 791-794.

Dannaoui E, Meletiadis J, Mouton JW, Meis JF, Verweij PE, Eurofung N. 2003. In vitro susceptibilities of zygomycetes to conventional and new antifungals. J Antimicrob Chemother 51: 45-52.

Dannaoui E, Schwarz P, Lortholary O. 2009. In vitro interactions between antifungals and immunosuppressive drugs against zygomycetes. Antimicrob Agents Chemother 53: 3549-3551.

de Aguiar E, Moraes W, Londero AT. 1980. Gastrointestinal entomophthoramycosis caused by Basidiobolus haptosporus. Mycopathologia 72: 101-105.

de Hoog GS, Cuarro J, Gené J, Figueras MJ. 2000. Atlas of clinical fungi, 2nd ed. CBS, Utrecht, The Netherlands.

de Locht M, Boelaert JR, Schneider YJ. 1994. Iron uptake from ferrioxamine and from ferrirhizoferrin by germinating spores of Rhizopus microsporus. Biochem Pharmacol 47: 1843-1850.

de Paula DA, de Oliveira Filho JX, da Silva MC, Colodel EM, Broetto L, Pinto PM, Schrank A, Nakazato L, Dutra V. 2010. Molecular characterization of ovine zygomycosis in central western Brazil. J Vet Diagn Invest 22: 274-277.

Diamond RD, Clark RA. 1982. Damage to Aspergillus fumigatus and Rhizopus oryzae hyphae by oxidative and nonoxidative microbicidal products of human neutrophils in vitro. Infect Immun 38: 487-495.

Diamond RD, Haudenschild CC, Erickson NF III. 1982. Monocyte-mediated damage to Rhizopus oryzae hyphae in vitro. Infect Immun 38: 292-297.

Diekema DJ, Messer SA, Hollis RJ, Jones RN, Pfaller MA. 2003. Activities of caspofungin, itraconazole, posaconazole, ravuconazole, voriconazole, and amphotericin B against 448 recent clinical isolates of filamentous fungi. J Clin Microbiol 41: 3623-3626. 
Donnelly JP, Lahav M. 2012. Deferasirox as adjunctive therapy for mucormycosis. J Antimicrob Chemother 67: 519520.

Drechsler C. 1947. Basidiobolus producing elongated secondary conidia with adhesive beaks. Bull Torrey Bot Club 74: 403-413.

Drechsler C. 1953. Production by Basidiobolus spp. of odor familiar in Streptomyces spp. and in benzene hexachloride (Abstract). Phytopathology 43: 405.

Drechsler C. 1956. Supplementary development stages of Basidiobolus ranarum and Basidiobolus haptosporus. Mycologia 48: 655-676.

Dromer F, McGinnis MR. 2003. Zygomycosis. In Clinical mycology (ed. Anaissie EJ, et al.), pp. 297-308. Churchill Livingstone, New York.

Drummond AJ, Suchard MA, Xie D, Rambaut A. 2012. Bayesian phylogenetics with BEAUti and the BEAST 1.7. Mol Biol Evol 29: 1969-1973.

Dworzack DL, Pollock AS, Hodges GR, Barnes WG, Ajello L, Padhye A. 1978. Zygomycosis of the maxillary sinus and palate caused by Basidiobolus haptosporus. Arch Intern Med 138: 1274-1276.

Dykstra MJ. 1994. Ballistosporic conidia in Basidiobolus ranarum: The influence of light and nutrition on the production of conidia and endospores (sporangiospores) Mycologia 86: 494-501.

Eckert HL, Khoury GH, Pore RS, Gilbert EF, Gaskell JR. 1972. Deep Entomophthora phycomycotic infection reported for the first time in the United States. Chest 61: 392-394.

Edington GM. 1964. Phycomycosis in Ibadan, western Nigeria: Two postmortem reports. Trans $R$ Soc Trop Med Hyg 58: 242-245.

Eidam E. 1886. Basidiobolus eineneue gattung der Entomophthoracean. Beitr BioI Pflanz 4: 181-251.

Espinel-Ingroff A. 2003. In vitro antifungal activities of anidulafungin and micafungin, licensed agents and the investigational triazole posaconazole as determined by NCCLS methods for 12,052 fungal isolates: Review of the literature. Rev Iberoam Micol 20: 121-136.

Etienne KA, Gillece J, Hilsabeck R, Schupp JM, Colman R, Lockhart SR, Gade L, Thompson EH, Sutton DA, Neblett-Fanfair R, et al. 2012. Whole genome sequence typing to investigate the Apophysomyces outbreak following a tornado in Joplin, Missouri, 2011. PLoS ONE 7: e49989.

Evriviades D, Jeffery S, Cubison T, Lawton G, Gill M, Mortiboy D. 2011. Shaping the military wound: Issues surrounding the reconstruction of injured servicemen at the Royal Centre for Defence Medicine. Philos Trans $R$ Soc Lond B Biol Sci 366: 219-230.

Fischer N, Ruef C, Ebnöther CB, Bächli EB. 2008. Rhinofacial Conidiobolus coronatus infection presenting with nasal enlargement. Infection 36: 594-596.

Fitzpatrick HM. 1930. The lower fungi; Phycomycetes. McGraw-Hill, New York.

Fomufod AR, Antia AO. 1971. Successful treatment of subcutaneous phycomycosis with trimenhoprim-sulfamentoxazole (septrin). Trop Georg Med 23: 208-211.

Fromentin H, Ravisse P. 1977. Tropical entomophthoromycoses. Acta Trop 34: 375-394.
Gartenberg G, Bottone EJ, Keusch GT, Weitzman I. 1978. Hospital-acquired mucormycosis (Rhizopus rhizopodiformis) of skin and subcutaneous tissue: Epidemiology, mycology and treatment. N Engl J Med 299: 1115-1118.

Gebremariam T, Liu M, Luo G, Bruno V, Phan QT, Waring AJ, Edwards JJE, Filler SG, Yeaman MR, Ibrahim AS 2014. CotH3 mediates fungal invasion of host cells during mucormycosis. J Clin Invest 124: 237-250.

Gilbert EF, Khoury EM, Pore RS. 1970. Histopathological identification of Entomophthora phycomycosis. Deep mycotic infection in an infant. Arch Pathol 90: 583-587.

Gleissner B, Schilling A, Anagnostopolous I, Siehl I, Thiel E. 2004. Improved outcome of zygomycosis in patients with hematological diseases? Leuk Lymphoma 45: 1351-1360.

Gonzalez CE, Couriel DR, Walsh TJ. 1997. Disseminated zygomycosis in a neutropenic patient: Successful treatment with amphotericin B lipid complex and granulocyte colony-stimulating factor. Clin Infect Dis 24: $192-$ 196.

Greenberg RN, Mullane K, van Burik JAH, Raad I, Abzug MJ, Anstead G, Herbrecht R, Langston A, Marr KA, Schiller G, et al. 2006. Posaconazole as salvage therapy for zygomycosis. Antimicrob Agents Chemother 50: 126-133.

Greer DL, Friedman L. 1966. Studies on the genus Basidiobolus with reclassification of the species pathogenic for man. Sabouraudia 4: 2310241.

Grigull L, Beilken A, Schmid H, Kirschner P, Sykora K-W, Linderkamp C, Donnerstag F, Goudeva L, Heuft H-G, Welte K. 2006. Secondary prophylaxis of invasive fungal infections with combination antifungal therapy and GCSF-mobilized granulocyte transfusions in three children with hematological malignancies. Support Care Cancer 14: 783-786.

Groff JM, Mughannam A, McDowell TS, Wong A, Dykstra MJ, Frye FL, Hedrick RP. 1991. An epizootic of cutaneous zygomycosis dwarf African clawed frogs (Hymenochris curtipes) due to Basidiobolus ranarum. J Med Vet Mycol 29: $215-253$.

Groll AH, Giri N, Petraitis V, Petraitiene R, Candelario M, Bacher JS, Piscitelli SC, Walsh TJ. 2000. Comparative efficacy and distribution of lipid formulations of amphotericin B in experimental Candida albicans infection of the central nervous system. J Infect Dis 182: 274-282.

Gryganskyi AP, Lee SC, Litvintseva AP, Smith ME, Bonito G, Porter TM, Anishchenko IM, Heitman J, Vilgalys R. 2010. Structure, function, and phylogeny of the mating locus in the Rhizopus oryzae complex. PLoS ONE 5: e15273.

Gryganskyi AP, Humber RA, Smith ME, Hodge K, Huang B, Voigt K, Vilgalys R. 2013. Phylogenetic lineages in Entomophthoromycota. Persoonia 30: 94-105.

Guarro J, Gene J, Stchigel AM. 1999. Developments in fungal taxonomy. Clin Microbiol Rev 12: 454-500.

Gugnani HC. 1999. A review of zygomycosis due to Basidiobolus ranarum. Eur J Epidermiol 15: 923-929.

Guinea J, Pelaez T, Recio S, Torres-Narbona M, Bouza E. 2008. In vitro antifungal activities of isavuconazole (BAL4815), voriconazole, and fluconazole against 1,007 isolates of zygomycete, Candida, Aspergillus, Fusarium, and Scedosporium species. Antimicrob Agents Chemother 52: $1396-1400$. 
L. Mendoza et al.

Hassan H, Majid R, Rashid N, Nuradeen B, Abdulkarim Q, Hawramy T, Rashid R, Farris A, Guarner J, Hughson M. 2013. Eosinophilic granulomatous gastrointestinal and hepatic abscesses attributable to basidiobolomycosis and fasciolias: A simultaneous emergence in Iraqi Kurdistan. BMC Infect Dis 13: 91.

Heckman DS, Geiser DM, Eidell BR, Stauffer RL, Kardos NL, Hedges SB. 2001. Molecular evidence for the early colonization of land by fungi and plants. Science 293: 1129-1133.

Helderman JH, Cooper HS, Mann J. 1974. Letter: Chronic phycomycosis in a controlled diabetic. Ann Intern Med 80: 419 .

Henk DA, Fisher MC. 2012. The gut fungus Basidiobolus ranarum has a large genome and different copy numbers of putatively functionally redundant elongation factors genes. PLoS ONE 7: e31268.

Hernandez MJ, Landaeta W, Salazar BN, Vargas J, Rodriguez-Morales AJ. 2007. Subcutaneous zygomycosis due to Conidiobolus incongruus. Int J Infect Dis 11: 468-469.

Hoffmann K, Telle S, Walther G, Eckart M, Kirchmair M, Prillinger HJ, Prazenica A, Newcombe G, Dölz F, Papp T, et al. 2009. Diversity, genotypic identification, ultrastructural and phylogenetic characterization of zygomycetes from different ecological habitats and climatic regions: Limitations and utility of nuclear ribosomal DNA barcode markers. In Current advances in molecular mycology (ed. Gherbawy Y, et al.), pp. 263-312. Nova, New York.

Hoffmann K, Pawlowska J, Walther G, Wrzosek M, de Hoog GS, Benny GL, Kirk PM, Voigt K. 2013. The family structure of the Mucorales: A synoptic revision based on comprehensive multigene-genealogies. Persoonia 30: 57-76.

Howard DH. 1999. Acquisition, transport, and storage of iron by pathogenic fungi. Clin Microbiol Rev 12: 394404.

Humber RA, Brown CC, Kornegay RW. 1989. Equine zygomycosis caused by Conidiobolus lamprauges. J Clin Microbiol 27: 573-576.

Hung C-Y, Xue J, Cole GT. 2007. Virulence mechanisms of Coccidioides. Ann NY Acad Sci 1111: 225-235.

Huppert M, Sun SH, Harrison JL. 1982. Morphogenesis throughout saprobic and parasitic cycles of Coccidioides immitis. Mycopathologia 78: 107-122.

Ibrahim AS, Spellberg B. 2006. Zygomycetes as agents of infectious disease in humans. In Molecular principles of fungal pathogenesis (ed. Heitman J, et al.), pp. 429-440. ASM, Washington, DC.

Ibrahim AS, Avanessian V, Spellberg B, Edwards JE Jr. 2003. Liposomal amphotericin B, and not amphotericin B deoxycholate, improves survival of diabetic mice infected with Rhizopus oryzae. Antimicrob Agents Chemother 47: 3343-3344.

Ibrahim AS, Bowman JC, Avanessian V, Brown K, Spellberg B, Edwards JE Jr, Douglas CM. 2005a. Caspofungin inhibits Rhizopus oryzae 1,3- $\beta$-D-glucan synthase, lowers burden in brain measured by quantitative PCR, and improves survival at a low but not a high dose during murine disseminated zygomycosis. Antimicrob Agents Chemother 49: 721-727.

Ibrahim AS, Spellberg B, Avanessian V, Fu Y, Edwards JE Jr. 2005b. Rhizopus oryzae adheres to, is phagocytosed by, and damages endothelial cells in vitro. Infect Immun 73: 778-783.

Ibrahim AS, Edwards JE Jr, Fu Y, Spellberg B. 2006. Deferiprone iron chelation as a novel therapy for experimental mucormycosis. J Antimicrob Chemother 58: 1070-1073.

Ibrahim AS, Gebermariam T, Fu Y, Lin L, Husseiny MI, French SW, Schwartz J, Skory CD, Edwards JE Jr, Spellberg BJ. 2007. The iron chelator deferasirox protects mice from mucormycosis through iron starvation. J Clin Invest 117: 2649-2657.

Ibrahim AS, Edwards JE, Bryant R, Spellberg B. 2008a. Economic burden of mucormycosis in the United States: Can a vaccine be cost-effective? Med Mycol 47: 592-600.

Ibrahim AS, Gebremariam T, Fu Y, Edwards JE Jr, Spellberg B. 2008b. Combination echinocandin-polyene treatment of murine mucormycosis. Antimicrob Agents Chemother 52: $1556-1558$.

Ibrahim AS, Gebremariam T, Husseiny MI, Stevens DA, Fu Y, Edwards JE, Spellberg B. 2008c. Comparison of lipid amphotericin B preparations in treating murine zygomycosis. Antimicrob Agents Chemother 52: 1573-1576.

Ibrahim AS, Spellberg B, Edwards J Jr. 2008d. Iron acquisition: A novel perspective on mucormycosis pathogenesis and treatment. Curr Opin Infect Dis 21: 620-625.

Ibrahim AS, Gebremariam T, Schwartz JA, Edwards JE Jr, Spellberg B. 2009. Posaconazole mono- or combination therapy for the treatment of murine zygomycosis. Antimicrob Agents Chemother 53: 772-775.

Ibrahim AS, Spellberg B, Walsh TJ, Kontoyiannis DP. 2012. Pathogenesis of mucormycosis. Clin Infect Dis 54: S16S22.

Imhof A, Balajee SA, Fredricks DN, Englund JA, Marr KA. 2004. Breakthrough fungal infections in stem cell transplant recipients receiving voriconazole. Clin Infect Dis 39: $743-746$.

Ingold CT. 1934. The spore discharge mechanism in Basidiobolus ranarum. Phytologist 33: 274-277.

Isa-Isa R, Arenas R, Fernandez RF, Isa M. 2012. Rhinofacial conidiobolomycosis (entomophthoramycosis). Clin Dermatol 30: 409-412.

James TY, Kauff F, Schoch CL, Matheny PB, Hofstetter V, Cox CJ, Celio G, Gueidan C, Fraker E, Miadlikowska J, et al. 2006. Reconstructing the early evolution of fungi using a six-gene phylogeny. Nature 443: 818-822.

Jensen AB, Gargas A, EilenbergJr, RosendahlSr. 1998. Relationships of the insect-pathogenic order Entomophthorales (Zygomycota, Fungi) based on phylogenetic analyses of nuclear small subunit ribosomal DNA sequences (SSU rDNA). Fungal Genet Biol 24: 325-334.

Jorens PG, Boelaert JR, Halloy V, Zamora R, Schneider YJ, Herman AG. 1995. Human and rat macrophages mediate fungistatic activity against Rhizopus species differently: In vitro and ex vivo studies. Infect Immun 63: 4489-4494.

Joshi N, Caputo GM, Weitekamp MR, Karchmer AW. 1999. Infections in patients with diabetes mellitus. $N$ Engl J Med 341: 1906-1912.

Kamalam A, Thambiah AS. 1979. Entomothoramycosis basidiobolae successfully treated with KI. Mykosen 22: 82-84.

Kamalam A, Thambiah AS. 1982. Muscle invasion by Basidiobolus haptosporus. Sabouraudia 22: 273-277. 
Kaufman L, Mendoza L, Standard PG. 1990. Immunodiffusion test for serodiagnosing subcutaneous zygomycosis. J Clin Microbiol 28: 1887-1890.

Kelly S, Gill N, Hutt MSR. 1980. Subcutaneous phycomycosis in Sierra Leone. Trans R Soc Trop Med Hyg 74: $396-$ 397.

Ketterer PJ, Kelly MA, Connole MD, Ajello L. 1992. Rhinocerebral and nasal zygomycosis in sheep caused by Conidiobolus incongruus. Aust Vet J 69: 85-87.

Khan ZU, Khoursheed M, Makar R, Al-Waheeb S, Al-Bader I, Al-Muzaini A, Chandy R, Mustafa AS. 2001. Basidiobolus ranarum as an etiologic agent of gastrointestinal zygomycosis. J Clin Microbiol 39: 2360-2363.

Kian Joe L, Pohan A, Tjoei Eng N, Van Der Meulen HH. 1956. Basidiobolus ranarum as a cause of subcutaneous mycosis in Indonesia. Arch Dermatol 74: 378-383.

Kimura M, Yaguchi T, Sutton DA, Fothergill AW, Thompson EH, Wickes BL. 2011. Disseminated human conidiobolomycosis due to Conidiobolus lamprauges. J Clin Microbiol 49: 752-756.

King DS. 1977. Systematics of Conidiobolus (Entomophthorales) using numerical taxonomy: III. Descriptions of recognized species. Can J Bot 55: 718-729.

King DS. 1983. Entomophthorales. In Fungi pathogenic for humans and animals, Part A (ed. Howard DH), pp. 61-72. Marcel Dekker, New York.

King DS, Jong SC. 1976. Identity of the etiological agent of the first deep entomophthoraceous infection of man in the United States. Mycologia 68: 181-183.

Kobayashi K, Kami M, Murashige N, Kishi Y, Fujisaki G, Mitamura T. 2004. Breakthrough zygomycosis during voriconazole treatment for invasive aspergillosis. Haematologica 89: ECR42-ECR42.

Kontoyiannis DP, Wessel VC, Bodey GP, Rolston KV. 2000 Zygomycosis in the 1990s in a tertiary-care cancer center. Clin Infect Dis 30: 851-856.

Kontoyiannis DP, Lionakis MS, Lewis RE, Chamilos G, Healy M, Perego C, Safdar A, Kantarjian H, Champlin R, Walsh TJ, et al. 2005. Zygomycosis in a tertiary-care cancer center in the era of Aspergillus-active antifungal therapy: A case-control observational study of 27 recent cases. J Infect Dis 191: 1350-1360.

Kontoyiannis DP, Marr KA, Park BJ, Alexander BD, Anaissie EJ, Walsh TJ, Ito J, Andes DR, Baddley JW, Brown JM, et al. 2010. Prospective surveillance for invasive fungal infections in hematopoietic stem cell transplant recipients, 2001-2006: Overview of the Transplant-Associated Infection Surveillance Network (TRANSNET) Database. Clin Infect Dis 50: 1091-1100.

Koshi G, Kurien T, Sundarsnam D, Selvapandian AJ, Mamen KE. 1972. Subcutaneous phycomycosis caused by $\mathrm{Ba}-$ sidiobolus: Report of three cases. Sabouraudia 10: 237 247.

Krings M, Taylor TN, Dotzler N. 2013. Fossil evidence of the zygomycetous fungi. Persoonia 30: 1-10.

Krishna G, Martinho M, Chandrasekar P, Ullmann AJ, Patino H. 2007a. Pharmacokinetics of oral posaconazole in allogeneic hematopoietic stem cell transplant recipients with graft-versus-host disease. Pharmacotherapy 27: 1627-1636.
Krishna G, Parsons A, Kantesaria B, Mant T. 2007b. Evaluation of the pharmacokinetics of posaconazole and rifabutin following co-administration to healthy men. Curr Med Res Opin 23: 545-552.

Krishna G, Sansone-Parsons A, Martinho M, Kantesaria B, Pedicone L. 2007c. Posaconazole plasma concentrations in juvenile patients with invasive fungal infection. Antimicrob Agents Chemother 51: 812-818.

Krishnan SG, Sentamilselvi G, Kamalam A, Das KA, Janaki C. 1998. Entomophthoromycosis in India-A 4-year study. Mycoses 41: 55-58.

Kullberg BJ, Anaissie EJ. 1998. Cytokines as therapy for opportunistic fungal infections. Res Immunol 149: $478-488$.

Kwon-Chung KJ. 2012. Taxonomy of fungi causing mucormycosis and entomophthoramycosis (zygomycosis) and nomenclature of the disease: Molecular mycologic perspectives. Clin Infect Dis 54: S8-S15.

Kwon-Chung KJ, Bennett JE. 1992. Mucormycosis. In Medical mycology (ed. Kwon-Chung KJ, Bennett JE), pp. 524559. Lea \& Febiger, Philadelphia.

Lamaris GA, Ben-Ami R, Lewis RE, Chamilos G, Samonis G, Kontoyiannis DP. 2009. Increased virulence of zygomycetes organisms following exposure to voriconazole: A study involving fly and murine models of zygomycosis. J Infect Dis 199: 1399-1406.

Langford JD, McCartney DL, Wang RC. 1997. Frozen section-guided surgical debridement for management of rhino-orbital mucormycosis. Am J Ophthalmol 124: 265-267.

Lanternier F, Lortholary O. 2009. Zygomycosis and diabetes mellitus. Clin Microbiol Infect 15: 21-25.

Lanternier F, Dannaoui E, Morizot G, Elie C, Garcia-Hermoso D, Huerre M, Bitar D, Dromer F, Lortholary O; the French Mycosis Study G. 2012a. A global analysis of mucormycosis in France: The RetroZygo study (20052007). Clin Infect Dis 54: S35-S43.

Lanternier F, Sun H-Y, Ribaud P, Singh N, Kontoyiannis DP, Lortholary O. 2012b. Mucormycosis in organ and stem cell transplant recipients. Clin Infect Dis 54: 1-8.

Lee SC, Ni M, Li W, Shertz C, Heitman J. 2010. The evolution of sex: A perspective from the fungal kingdom. $M i-$ crobiol Mol Biol Rev 74: 298-340.

Lee SC, Li A, Calo S, Heitman J. 2013. Calcineurin plays key roles in the dimorphic transition and virulence of the human pathogenic zygomycete Mucor circinelloides. PLoS Pathog 9: el003625.

Levisohn I. 1927. Beitrag zur Entwichlungsgeschichte und Biologie von Basidiobolus ranarum Eidam. Jahrb Wiss Bot 66: 513-555.

Levitz SM, Selsted ME, Ganz T, Lehrer RI, Diamond RD. 1986. In vitro killing of spores and hyphae of Aspergillus fumigatus and Rhizopus oryzae by rabbit neutrophil cationic peptides and bronchoalveolar macrophages. J Infect Dis 154: $483-489$.

Lewis RE, Ben-Ami R, Best L, Albert N, Walsh TJ, Kontoyiannis DP. 2013. Tacrolimus enhances the potency of posaconazole against Rhizopus oryzae in vitro and in an experimental model of mucormycosis. J Infect Dis 207: $834-841$. 
L. Mendoza et al.

Li CH, Cervantes M, Springer DJ, Boekhout T, Ruiz-Vazquez RM, Torres-Martinez SR, Heitman J, Lee SC. 2011. Sporangiospore size dimorphism is linked to virulence of Mucor circinelloides. PLoS Pathog 7: e1002086.

Liu M, Spellberg B, Phan QT, Fu Y, Fu Y, Lee AS, Edwards JE, Filler SG, Ibrahim AS. 2010. The endothelial cell receptor GRP78 is required for mucormycosis pathogenesis in diabetic mice. J Clin Invest 120: 1914-1924.

Londero AT, Aroiyo MGS, Mendonca N, Bostos JLA. 1979. Occurrence of subcutaneous zygomycosis caused by $\mathrm{Ba}$ sidiobolus haptosporus in Brazil. Mycopathologia 68: $101-$ 104.

Luo G, Gebremariam T, Lee H, Edwards JE Jr, Ibrahim AS. 2013a. Isavucoazole protects immunosuppressed mice from Rhizopus oryzae infection, abstr. M-787. In 53rd Interscience conference on antimicrobial agents and chemotherapy. American Society for Microbiology, Washington, DC.

Luo G, Gebremariam T, Lee H, French SW, Wiederhold NP, Patterson TF, Filler SG, Ibrahim AS. 2013b. Efficacy of liposomal amphotericin B and posaconazole in intratracheal models of murine mucormycosis. Antimicrob Agents Chemother 57: 3340-3347.

Ma B, Seymour JF, Januszewicz H, Slavin MA. 2001. Cure of pulmonary Rhizomucor pusillus infection in a patient with hairy-cell leukemia: Role of liposomal amphotericin B and GM-CSF. Leuk Lymphoma 42: 1393-1399.

Ma L-J, Ibrahim AS, Skory C, Grabherr MG, Burger G, Butler M, Elias M, Idnurm A, Lang BF, Sone T, et al. 2009. Genomic analysis of the basal lineage fungus Rhizopus oryzae reveals a whole-genome duplication. PLoS Genet 5: e1000549.

Madson D, Loynachan AT, Kariyawasam S, Opriessning T 2009. Systemic Conidiobolus incongruus infection and hypertrophic osteopathy in a white-tailed deer (Odocoileus virginianus). J Vet Diagn Invest 21: 167-170.

Maertens J, Demuynck H, Verbeken EK, Zachee P, Verhoef GE, Vandenberghe P, Boogaerts MA. 1999. Mucormycosis in allogeneic bone marrow transplant recipients: Report of five cases and review of the role of iron overload in the pathogenesis. Bone Marrow Transplant 24: 307-312.

Martinson FD, Clark BM. 1967. Rhinophycomycosis entomophthorae in Nigeria. Am J Trop Med Hyg 16: 40-47.

Marty FM, Cosimi LA, Baden LR. 2004. Breakthrough zygomycosis after voriconazole treatment in recipients of hematopoietic stem-cell transplants. N Engl J Med 350: 950-952.

Mastroianni A. 2004. Paranasal sinus mucormycosis in an immunocompetent host: Efficacy and safety of combination therapy with liposomal amphotericin B and adjuvant rHuGM-CSF. Infez Med 12: 278-283.

McGinnis MR. 1980. Recent taxonomic developments and changes in medical mycology. Annu Rev Microbiol 34: 109-135.

Mead JH, Lupton GP, Dillavou CL, Odom RB. 1979. Cutaneous Rhizopus infection. Occurrence as a postoperative complication associated with an elasticized adhesive dressing. JAMA 242: 272-274.

Mendoza L, Alfaro AA. 1985. Equine subcutaneous zygomycosis in Costa Rica. Mykosen 28: 545-549.
Mendoza L, Newton JC. 2005. Immunology and immunotherapy of the infections caused by Pythium insidiosum. Med Mycol 43: 477-486.

Mendoza L, Vilela R. 2013. The mammalian pathogenic oomycetes. Curr Fungal Infect Rep 7: 198-208.

Mendoza L, Nicholson V, Prescott JF. 1992. Immunoblot analysis of the humoral immune response to Pythium insidiosum in horses with pythiosis. J Clin Microbiol 30: 2980-2983.

Miller RI. 1985. Gastrointestinal phycomycosis in 63 dogs. J Am Vet Med Assoc 186: 473-478.

Miller RI, Campbell RSF. 1982. Clinical observations on equine phycomysis. Aust Vet J 58: 221-226.

Miller RI, Campbell RSF. 1984. The comparative pathology of equine cutaneous phycomycosis. Vet Pathol 21: 325332.

Narreddy S, Manavathu E, Chandrasekar PH, Alangaden GJ, Revankar SG. 2010. In vitro interaction of posaconazole with calcineurin inhibitors and sirolimus against zygomycetes. J Antimicrob Chemother 65: 701-703.

Nazir Z, Hasan R, Pervaiz S, Alam M, Moazam F. 1997. Invasive retroperitoneal infection due to Basidiobolus ranarum with response to potassium iodide-Case report and review of literature. Ann Trop Paediatr 17: 161-164.

Neblett Fanfair R, Benedict K, Bos J, Bennett SD, Lo Y-C, Adebanjo T, Etienne K, Deak E, Derado G, Shieh W-J, et al. 2012. Necrotizing cutaneous mucormycosis after a tornado in Joplin, Missouri, in 2011. N Engl J Med 367: 2214-2225.

Nie Y, Yu C-Z, Liu X-Y, Huang B. 2012. A new species of Conidiobolus (Ancylistacea) from Anhui, China. Mycotaxon 120: 427-435.

Nithyanandam S, Jacob MS, Battu RR, Thomas RK, Correa MA, D'Souza O. 2003. Rhino-orbito-cerebral mucormycosis. A retrospective analysis of clinical features and treatment outcomes. Indian J Ophthalmol 51: 231-236.

Okagaki LH, Strain AK, Nielsen JN, Charlier C, Baltes NJ, Chretien F, Heitman J, Dromer F, Nielsen K. 2010. Cryptococcal cell morphology affects host cell interactions and pathogenicity. PLoS Pathog 6: e1000953.

Onuigbo WIB, Gugnani HC. 1976. Deep mycoses prevalent in the Igbos of Nigeria. Int J Dermatol 15: 432-437.

Oren I. 2005. Breakthrough zygomycosis during empirical voriconazole therapy in febrile patients with neutropenia. Clin Infect Dis 40: 770-771.

Owen WR, Miller RI, Haynes PF, Snider TGI. 1985. Phycomycosis caused by Basidiobolus haptosporus in two horses. J Am Vet Med Ass 186: 161-164.

Pasha TM, Leighton JA, Smilack JD, Heppel J, Colby TV, Kaufman L. 1997. Basidiobolomycosis: An unusual fungal infection mimicking inflammatory bowel disease. Gastroenterology 112: 250-254.

Petrikkos GL. 2008. Zygomycosis (Mucormycosis): An emerging or re-emerging disease? Mycol Newsl 1: 31-32.

Petrikkos G, Skiada A, Lortholary O, Roilides E, Walsh TJ, Kontoyiannis DP. 2012. Epidemiology and clinical manifestations of mucormycosis. Clin Infect Dis 54: S23-S34.

Prabhu RM, Patel R. 2004. Mucormycosis and entomophthoramycosis: A review of the clinical manifestations, diagnosis and treatment. Clin Microbiol Infect 10:31-47. 
Randhawa HS, Budimulja U, Bazaz-Malik G, Bramono K, Hiruma M, Kullavanijaya P, Rojanavanich V. 1994. Recent developments in the diagnosis and treatment of subcutaneous mycoses. Med Mycol 32: 299-307.

Reed C, Bryant R, Ibrahim AS, Edwards J, Filler SG, Goldberg R, Spellberg B. 2008. Combination polyene-caspofungin treatment of rhino-orbital-cerebral mucormycosis. Clin Infect Dis 47: 364-371.

Ribeiro EFO, dos Santos VM, Paixão GTG, Cruz LR, Danilow MZ, Campos VF. 2013. Mucormycosis in a patient with acute myeloid leukemia successfully treated with liposomal amphotericin B associated with deferasirox and hyperbaric oxygen. Mycopathologia 175: 295-300.

Ribes JA, Vanover-Sams CL, Baker DJ. 2000. Zygomycetes in human disease. Clin Microbiol Rev 13: 236-301.

Riet-Correa F, Dantas AFM, Azevedo EO, Simões SDV, Silva S, Vilela R, Mendoza L. 2008. Outbreaks of rhinofacial and rhinopharyngeal zygomycosis in sheep in Paraíba, northeastern Brazil. Pesq Vet Bras 28: 29-35.

Robb SM. 1966. Reactions of fungi to exposure to 10 atmospheres pressure of oxygen. J Gen Microbiol 45: 17-29.

Roden MM, Zaoutis TE, Buchanan WL, Knudsen TA, Sarkisova TA, Schaufele RL, Sein M, Sein T, Chiou CC, Chu $\mathrm{JH}$, et al. 2005. Epidemiology and outcome of zygomycosis: A review of 929 reported cases. Clin Infect Dis 41: 634-653.

Rodriguez MM, Serena C, Marine M, Pastor FJ, Guarro J. 2008. Posaconazole combined with amphotericin B, an effective therapy for a murine disseminated infection caused by Rhizopus oryzae. Antimicrob Agents Chemother 52: 3786-3788.

Roilides E, Zaoutis TE, Walsh TJ. 2009. Invasive zygomycosis in neonates and children. Clin Microbiol Infect 15: 5054.

Saka B, Kombaté K, Mouhari-Toure A, Akakpo S, Tchangai B, Amégbor K, Pitché P, Tchangaï-Walla K. 2010. Basidiobolomycose probable chez un jeune rural togolais traitee avec succes par du ketoconazole. Bull Soc Pathol Exot 103: 293-295.

Salas V, Pastor FJ, Calvo E, Alvarez E, Sutton DA, Mayayo E, Fothergill AW, Rinaldi MG, Guarro J. 2012. In vitro and in vivo activities of posaconazole and amphotericin $B$ in a murine invasive infection by Mucor circinelloides: Poor efficacy of posaconazole. Antimicrob Agents Chemother 56: $2246-2250$.

Santiago AL, Hoffmann K, Lima DX, de Oliveira RV, Vieira HE, Malosso E, Maia LC, da Silva GA. 2014. A new species of Lichtheimia (Mucoromycotina, Mucorales) isolated from Brazilian soil. Mycol Prog 13: 343-352.

Schmidt JH, Howard RJ, Chen JL, Pierson K. 1986. First culture-proven gastrointestinal entomophthoromycosis in the United States. A case report and review of literature. Mycopathologia 95: 101-104.

Schrödl W, Heydel T, Schwartze VU, Hoffmann K, GrosseHerrenthey A, Walther G, Alastruey-Izquierdo A, Rodriguez-Tudela JL, Olias P, Jacobsen ID, et al. 2012. Direct analysis and identification of pathogenic Lichtheimia species by matrix-assisted laser desorption ionizationtime of flight analyzer-mediated mass spectrometry. J Clin Microbiol 50: 419-427.
Schussler A, Schwarzott D, Walker C. 2001. A new fungal phylum, the Glomeromycota: Phylogeny and evolution. Mycol Res 105: 1413-1421.

Schwartze VU, Winter S, Shelest E, Marcet-Houben M, Horn F, Wehner S, Linde J, Valiante V, Sammeth M, Riege $\mathrm{K}$, et al. 2014. Gene expansion shapes genome architecture in the human pathogen Lichtheimia corymbifera: An evolutionary genomics analysis in the ancient terrestrial Mucorales (Mucoromycotina). PLoS Genet (in press).

Singh N, Aguado JM, Bonatti H, Forrest G, Gupta KL, Safdar N, John GT, Pursell KJ, Munoz P, Patel R, et al. 2009. Zygomycosis in solid organ transplant recipients: A prospective, matched case-control study to assess risks for disease and outcome. J Infect Dis 200: 1002-1011.

Siwek GT, Dodgson KJ, de Magalhaes-Silverman M, Bartelt LA, Kilborn SB, Hoth PL, Diekema DJ, Pfaller MA. 2004. Invasive zygomycosis in hematopoietic stem cell transplant recipients receiving voriconazole prophylaxis. Clin Infect Dis 39: 584-587.

Skiada A, Pagano L, Groll A, Zimmerli S, Dupont B, Lagrou K, Lass-Florl C, Bouza E, Klimko N, Gaustad P, et al. 2011. Zygomycosis in Europe: Analysis of 230 cases accrued by the registry of the European Confederation of Medical Mycology (ECMM) Working Group on Zygomycosis between 2005 and 2007. Clin Microbiol Infect 17: 1859-1867.

Skiada A, Rigopoulos D, Larios G, Petrikkos G, Katsambas A. 2012. Global epidemiology of cutaneous zygomycosis. Clin Dermatol 30: 628-632.

Slavin MA, Kannan K, Buchanan MR, Sasadeusz J, Roberts AW. 2002. Successful allogeneic stem cell transplant after invasive pulmonary zygomycosis. Leuk Lymphoma 43: 437-439.

Soman R, Gupta N, Shetty A, Rodrigues C. 2012. Deferasirox in mucormycosis: Hopefully, not defeated. J Antimicrob Chemother 67: 783-784.

Spellberg B, Fu Y, Edwards JE Jr, Ibrahim AS. 2005. Combination therapy with amphotericin B lipid complex and caspofungin acetate of disseminated zygomycosis in diabetic ketoacidotic mice. Antimicrob Agents Chemother 49: $830-832$.

Spellberg B, Andes D, Perez M, Anglim A, Bonilla H, Mathisen GE, Walsh TJ, Ibrahim AS. 2009. Safety and outcomes of open-label deferasirox iron chelation therapy for mucormycosis. Antimicrob Agents Chemother 53: 3122-3125.

Spellberg B, Ibrahim AS, Chin-Hong PV, Kontoyiannis DP, Morris MI, Perfect JR, Fredricks D, Brass EP. 2012. The Deferasirox-AmBisome therapy for mucormycosis (DEFEAT Mucor) study: A randomized, double-blinded, placebo-controlled trial. J Antimicrob Chemother 67: 715-722.

Speranza M, Wierzchosl J, Alonso J, Bettucci L, MartínGonzález A, Ascaso C. 2010. Traditional and new microscopy techniques applied to the study of microscopic fungi included in amber. In Microscopy: Science, technology, application and education (ed. Méndez-Vilas A, Díaz J), pp. 1135-1145. Formatex, Badajoz, Spain.

Spreghini E, Orlando F, Giannini D, Barchiesi F. 2010. In vitro and in vivo activities of posaconazole against zygo- 
mycetes with various degrees of susceptibility. J Antimicrob Chemother 65: 2158-2163.

Srinivasan MC, Thirumalachar MJ. 1965. Basidiobolus species pathogenic for man. Sabouraudia 4: 32-34.

Sugar AM. 2005. Agents of mucormycosis and related species. In Principles and practice of infectious diseases, 6 th ed. (ed. Mandell GL, et al.), pp. 2973-2984. Elsevier, Philadelphia.

Sun QN, Fothergill AW, McCarthy DI, Rinaldi MG, Graybill JR. 2002. In vitro activities of posaconazole, itraconazole, voriconazole, amphotericin $\mathrm{B}$, and fluconazole against 37 clinical isolates of zygomycetes. Antimicrob Agents Chemother 46: 1581-1582.

Sun HY, Aguado JM, Bonatti H, Forrest G, Gupta KL, Safdar N, John GT, Pursell KJ, Muñoz P, Patel R, et al. 2009. Pulmonary zygomycosis in solid organ transplant recipients in the current era. Am J Transplant 9: 2166-2171.

Tedder M, Spratt JA, Anstadt MP, Hegde SS, Tedder SD, Lowe JE. 1994. Pulmonary mucormycosis: Results of medical and surgical therapy. Ann Thorac Surg 57: 1044-1050.

Temple ME, Brady MT, Koranyi KI, Nahata MC. 2001. Periorbital cellulitis secondary to Conidiobolus incongruus. Pharmacotherapy 21: 351-354.

Thakur M, Revankar SG. 2011. In vitro interaction of caspofungin and immunosuppressives against agents of mucormycosis. J Antimicrob Chemother 66: 2312-2314.

Thasnakorn P, Sriboonma V, Chantrkul N, Bhadrakom S. 1969. Subcutaneous phycomycosis due to Basidiobolus meristosporus: Report of a case. J Med Assoc Thai 53: 372-377.

Tondolo JSM, Loreto âSd, Dutra Vr, Nakazato L, Paula DAJd, Zanette RgA, Alves SH, Santurio JM. 2013. In vitro susceptibility of Conidiobolus lampranges recovered from sheep to antifungal agents. Vet Microbiol 166: 690-693.

Trifilio S, Singhal S, Williams S, Frankfurt O, Gordon L, Evens A, Winter J, Tallman M, Pi J, Mehta J. 2007. Breakthrough fungal infections after allogeneic hematopoietic stem cell transplantation in patients on prophylactic voriconazole. Bone Marrow Transplant 40: 451-456.

Ullmann AJ, Cornely OA, Burchardt A, Hachem R, Kontoyiannis DP, Topelt K, Courtney R, Wexler D, Krishna G, Martinho M, et al. 2006. Pharmacokinetics, safety, and efficacy of posaconazole in patients with persistent febrile neutropenia or refractory invasive fungal infection. Antimicrob Agents Chemother 50: 658-666.

van Burik JA, Hare RS, Solomon HF, Corrado ML, Kontoyiannis DP. 2006. Posaconazole is effective as salvage therapy in zygomycosis: A retrospective summary of 91 cases. Clin Infect Dis 42: e61-e65.

Van Cutsem J, Boelaert JR. 1989. Effects of deferoxamine, feroxamine and iron on experimental mucormycosis (zygomycosis). Kidney Int 36: 1061-1068.

Van Overeem C. 1925. Uber ain merkwurdiges Vorkommen von Basidiobolus ranarum Eidam. Bull Jardin Bot 7: 423431.

Verweij PE, González GM, Wiederhold NP, Lass-Flörl C, Warn P, Heep M, Ghannoum MA, Guinea J. 2009. In vitro antifungal activity of isavuconazole against $345 \mathrm{Mu}$ corales isolates collected at study centers in eight countries. J Chemother 21: 272-281.
Vilela R, Silva SMS, Riet-Correa F, Dominguez E, Mendoza L. 2010. Morphologic and phylogenetic characterization of Conidiobolus lampragues recovered from infected sheep. J Clin Microbiol 48: 427-432.

Villasco J, Camain R, Mazère J, Orio J, Segretain G. 1966. D'um deuxieme cas de phycomycose en Cote-d'ivoire avec isolement de la souche. Bull Soc Pathol Exot 59: 781786.

Vismer HF, DeBeer HA, Dreyer L. 1980. Subcutaneous phycomycosis caused by Basidiobolus haptosporus (Drechsler, 1947). S Afr Med J 58: 644-647.

Vitale RG, de Hoog GS, Schwarz P, Dannaoui E, Deng S, Machouart M, Voigt K, van de Sande WWJ, Dolatabadi S, Meis JF, et al. 2012. Antifungal susceptibility and phylogeny of opportunistic members of the order Mucorales. J Clin Microbiol 50: 66-75.

Voigt K. 2012. Zygomycota. In Syllabus of plant families: Adolf Engler's Syllabus der Planzenfamilien (ed. Frey W), pp. 130-162. Borntraeger, Stuttgart, Germany.

Waldorf AR. 1989. Pulmonary defense mechanisms against opportunistic fungal pathogens. Immunol Ser 47: 243 271.

Waldorf AR, Diamond RD. 1985. Neutrophil chemotactic responses induced by fresh and swollen Rhizopus oryzae spores and Aspergillus fumigatus conidia. Infect Immun 48: $458-463$.

Waldorf AR, Levitz SM, Diamond RD. 1984a. In vivo bronchoalveolar macrophage defense against Rhizopus oryzae and Aspergillus fumigatus. J Infect Dis 150: 752-760.

Waldorf AR, Ruderman N, Diamond RD. 1984b. Specific susceptibility to mucormycosis in murine diabetes and bronchoalveolar macrophage defense against Rhizopus. J Clin Invest 74: $150-160$.

Walker SD, Clark RV, King CT, Humphries JE, Lytle LS, Butkus DE. 1992. Fatal disseminated Conidiobolus coronatus infection in a renal transplant patient. Am J Clin Pathol 98: 559-564.

Walsh TJ, Renshaw G, Andrews J, Kwon-Chung J, Cunnion RC, Pass HI, Taubenberger J, Wilson W, Pizzo PA. 1994. Invasive zygomycosis due to Conidiobolus incongruus. Clin Infect Dis 19: 423-430.

Walsh TJ, Finberg RW, Arndt C, Hiemenz J, Schwartz C, Bodensteiner D, Pappas P, Seibel N, Greenberg RN, Dummer S, et al. 1999. Liposomal amphotericin B for empirical therapy in patients with persistent fever and neutropenia. N Engl J Med 340: 764-771.

Wang D, Wu R, Xu Y, Li M. 2013. Draft genome sequence of Rhizopus chinensis CCTCCM201021, used for brewing traditional Chinese alcoholic beverages. Genome Announc 1: e00195-e00112.

Warkentien T, Rodriguez C, Lloyd B, Wells J, Weintrob A, Dunne JR, Ganesan A, Li P, Bradley W, Gaskins LJ, et al. 2012. Invasive mold infections following combat-related injuries. Clin Infect Dis 55: 1441-1449.

Weinberg ED. 1974. Iron and susceptibility to infectious disease. Science 184: 952-956.

Werner S, Persoh D, Rambold G. 2012. Basidiobolus haptosporus is frequently associated with the gamasid mite Leptogamasus obesus. Fungal Biol 116: 90-97.

Wuppenhorst N, Lee M-K, Rappold E, Kayser G, Beckervordersandforth J, de With K, Serr A. 2010. Rhino-orbito- 
cerebral zygomycosis caused by Conidiobolus incongruus in an immunocompromised patient in Germany. J Clin Microbiol 48: 4322-4325.

Yafetto L, Carroll L, Cui Y, Davis DJ, Fischer MWF, Henterly AC, Kessler JD, Kilroy HA, Shidler JB, Stolze-Rybczynski JL, et al. 2008. The fastest flights in nature: High-speed spore discharge mechanisms among fungi. PLoS ONE 3: e3237.

Yang X, Li Y, Zhou X, Wang Y, Geng S, Liu H, Yang Q, Lu X, Hiruma M, Sugita T, et al. 2010. Rhinofacial conidiobolomycosis caused by Conidiobolus coronatus in a Chinese rice farmer. Mycoses 53: 369-373.
Yangco BG, Okafor JI, TeStrake D. 1984. In vitro susceptibilities of human and wild-type isolates of Basidiobolus and Conidiobolus species. Antimicrob Agents Chemother 25: $413-416$.

Yangco BG, Nettlow A, Okafor JI, Park J, Te Strake D. 1986. Comparative antigenic studies of species of Basidiobolus and other medically important fungi. J Clin Microbiol 23: 679-682.

Zaragoza O, Garcia-Rodas R, Nosanchuk JD, CuencaEstrella M, Rodriguez-Tudela JL, Casadevall A. 2010. Fungal cell gigantism during mammalian infection. PLoS Pathog 6: e1000945. 


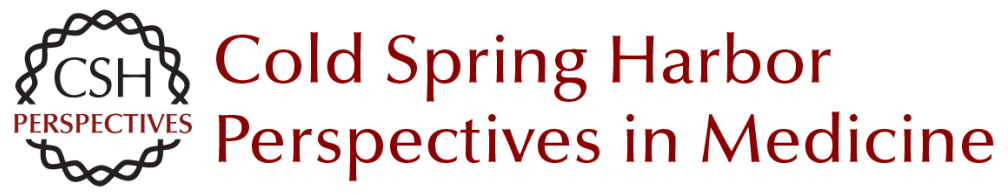

\section{Human Fungal Pathogens of Mucorales and Entomophthorales}

Leonel Mendoza, Raquel Vilela, Kerstin Voelz, Ashraf S. Ibrahim, Kerstin Voigt and Soo Chan Lee

Cold Spring Harb Perspect Med 2015; doi: 10.1101/cshperspect.a019562 originally published online November 6, 2014

Subject Collection Human Fungal Pathogens

\section{Evolutionary Perspectives on Human Fungal Pathogens John W. Taylor}

Black Molds and Melanized Yeasts Pathogenic to Humans Anuradha Chowdhary, John Perfect and G. Sybren de Hoog

Fungal Pathogens: Survival and Replication within Macrophages

Andrew S. Gilbert, Robert T. Wheeler and Robin C. May

Innate Defense against Fungal Pathogens Rebecca A. Drummond, Sarah L. Gaffen, Amy G. Hise, et al.

Antifungal Pharmacokinetics and

Pharmacodynamics

Alexander J. Lepak and David R. Andes

Human Fungal Pathogens of Mucorales and Entomophthorales

Leonel Mendoza, Raquel Vilela, Kerstin Voelz, et al.

Functional Profiling of Human Fungal Pathogen Genomes

Alexi I. Goranov and Hiten D. Madhani

Aspergillus fumigatus and Related Species Janyce A. Sugui, Kyung J. Kwon-Chung, Praveen R. Juvvadi, et al.
Thermally Dimorphic Human Fungal Pathogens--

Polyphyletic Pathogens with a Convergent

Pathogenicity Trait Anita Sil and Alex Andrianopoulos

Mechanisms of Antifungal Drug Resistance Leah E. Cowen, Dominique Sanglard, Susan J. Howard, et al.

Treatment Principles for Candida and Cryptococcus Laura C. Whitney and Tihana Bicanic

The Human Mycobiome Patrick C. Seed

Treatment Principles for the Management of Mold Infections

Dimitrios P. Kontoyiannis and Russell E. Lewis

Adaptive Immunity to Fungi Akash Verma, Marcel Wüthrich, George Deepe, et al.

The Candida Pathogenic Species Complex Siobhán A. Turner and Geraldine Butler

Fungal Morphogenesis Xiaorong Lin, J. Andrew Alspaugh, Haoping Liu, et al.

For additional articles in this collection, see http://perspectivesinmedicine.cshlp.org/cgi/collection/ 